\title{
Visual object categorisation at distinct levels of abstraction: A new stimulus set
}

\author{
Hans Op de Beeck, Johan Wagemans $\uparrow$ \\ University of Leuven, Department of Psychology, Tiensestraat 102, B 3000 Leuven, Belgium; \\ e-mail: johan.wagemans@psy.kuleuven.ac.be \\ Received 18 August 2000, in revised form 21 June 2001
}

\begin{abstract}
We designed a new stimulus set with 269 line drawings of everyday artifacts and animals. The stimulus set contains several typical exemplars from a sample of 25 basic-level categories. We determined to what extent these stimuli were named at the basic level and at a more subordinate level. An additional experiment showed the validity of this calibration: typicality ratings were correlated significantly with the level of naming. In a final experiment we found that this effect depends largely on the global configuration of a stimulus as it was still apparent with degraded images obtained by locally shifting small fragments of the drawings.
\end{abstract}

\section{Introduction}

Objects can be identified at several levels of abstraction. Rosch et al (1976) demonstrated the special status of one level of abstraction, called the basic level, at which most people tend to identify an object initially. Research with children and animals has pointed to the importance of visual features in determining the categories that are formed at different levels of abstraction (eg Behl-Chadha 1996; Markman 1989; Wasserman and Astley 1994). Moreover, behavioural and neuroimaging studies with adult subjects have shown that categorisation at a subordinate level requires more visual processing than categorisation at the basic level (eg Gauthier et al 1996; Jolicoeur et al 1984; Op de Beeck et al 2000).

If one wants to investigate the perceptual constraints on subordinate level categorisation, then one needs a stimulus set with several properties. First, we want simple line drawings as stimuli. There are many good reasons for this choice. Most studies mentioned above have used these stimuli. Also, for many stimuli, shape information is the most important attribute in subordinate-level categorisation (although there are exceptions, see Joseph and Proffitt 1996). Moreover, using line drawings instead of more complex gray-level or coloured pictures gives us more control on the information that is available to the subjects. Second, one would like to minimise the effect of nonperceptual features and the availability of salient subordinate names. Third, one needs a fairly high number of subordinate exemplars from each basic-level category. Fourth, the stimulus set should consist of a representative sample of basic-level categories. Fifth, one needs to know the proportion of names that are given to the stimuli at different levels of abstraction, based on a sufficient sample from the normal adult population.

The stimulus sets found in the literature do not match these criteria. The standard set of Snodgrass and Vanderwart (1980) was not designed to investigate multiple levels of categorisation and contains only one exemplar for each of a large number of concepts. Several studies (eg Farah et al 1995; Jolicoeur et al 1984; Marsolek 1999) have used sets of line drawings with several exemplars from different basic-level categories, but none of these sets had many exemplars from a range of categories, and little or no information is available about naming performance. In this paper, 
we present a stimulus set that was designed according to our guidelines. For each stimulus, we determined the percentage of subjects that named the stimulus spontaneously at a particular level of abstraction (either the basic level or a more subordinate level). Jolicoeur et al (1984) have introduced this 'abstraction of naming' as a measure of the 'entry point' of an object, that is, the level of abstraction at which an object is initially identified. They also pointed to the dependence of this entry point on the typicality of an exemplar for a category: more atypical exemplars are identified at a more subordinate level than more typical exemplars. The second and third experiments in the present paper show that this effect also exists in our stimulus set containing rather typical exemplars without very salient subordinate names. The existence of a salient subordinate name (eg 'chicken', 'penguin') is often confounded with high atypicality, a situation that induces semantic factors. Salient subordinate names are quite commonly related to particular subordinate categories with a consistent deviation from the typical members of a particular basic-level category. It is a relevant question whether the more subordinate naming of atypical exemplars is related to the availability of a salient subordinate name, or whether this effect will also be found in cases where such a salient label is not that obvious.

\section{Experiment 1: Calibration of the entry point}

\subsection{Methods}

2.1.1 Subjects. Four groups of students (total $N=357$ ) from the undergraduate program in psychology at the University of Leuven participated in this study as part of a course requirement.

2.1.2 Stimuli. The basic stimulus set contained 269 exemplars from 25 categories. A taxonomic diagram of the 25 categories is given in figure 1 . This diagram shows that the 25 categories are distributed across a wide range of all possible objects and can be considered as a fairly representative sample of objects (although the choice for the particular categories was made arbitrarily). We searched for exemplars without an obvious name more subordinate than the category label. Some categories consisted of 2 subcategories (eg the category 'sofa' is composed of 9 exemplars of 'couch' and
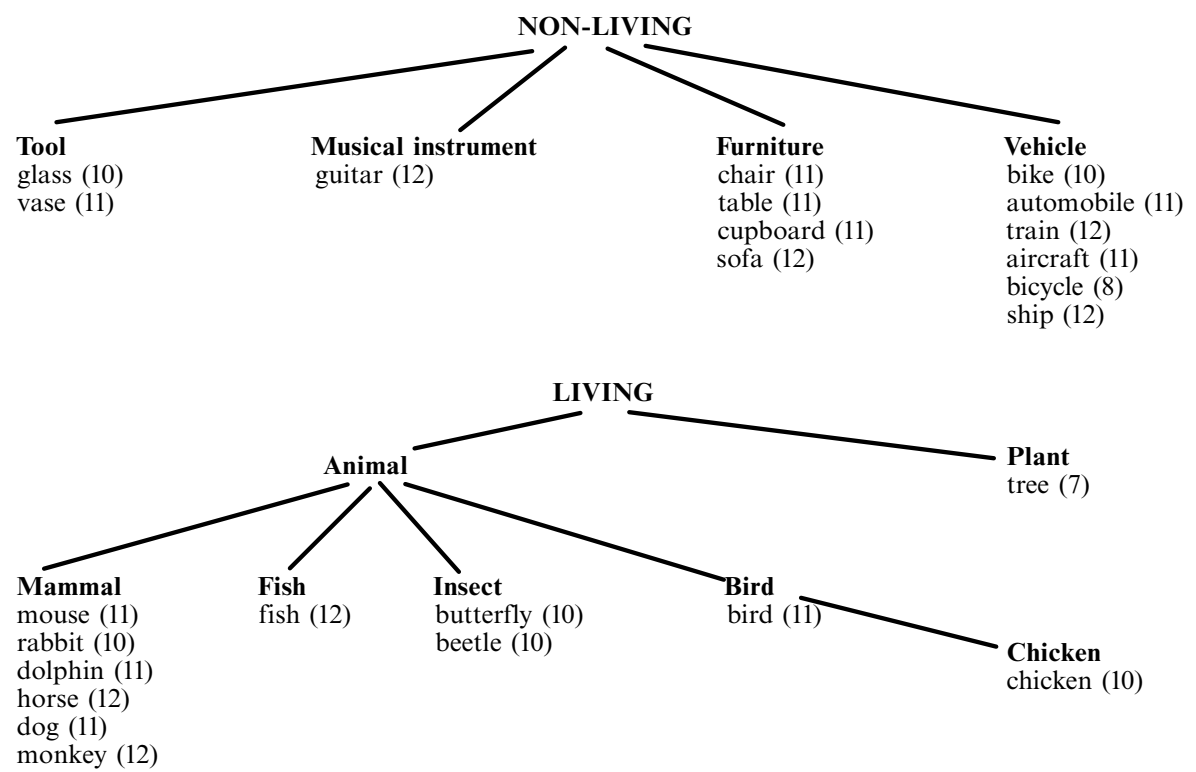

Figure 1. Taxonomy of the 25 categories in the stimulus set. The number of exemplars in each category is given in parentheses. 
3 exemplars of 'armchair'). Not all the categories were a priori considered to be basic-level categories. For example, both the categories 'chicken' and 'bird' are included. Moreover, two categories ('mouse' and 'dolphin') do not have a clear visual classification (ie the line drawings do not always contain enough information to differentiate these categories from others like 'rat' and 'fish', respectively).

Within a category, the exemplars were generally presented from the same perspective, but this rule did not hold completely between categories. For the categories that were also used by Rosch et al (1976), we used the perspective in which people mostly imagine an object. In the other categories, we tried to make the perspective similar both to the former categories and to the perspective in which the category is mainly presented in printed matter and in the standard set of Snodgrass and Vanderwart (1980). Using a consistent and standard perspective within and between categories avoids possible effects of this factor on categorisation performance.

The line drawings $(800 \times 600$ pixels $)$ consist of black lines on a white background. The drawings were generated by tracing from photos and drawings from encyclopedias and other standard collections. This was done to avoid the personal addition of stylistic variations that have been shown to affect naming latency (Brodie et al 1991; note that we calibrate and use only naming itself as a dependent variable, not its latency). Two images were made of each exemplar (an original and a mirror image). One image of all stimuli (called the 'left' image) can be found in Appendix A.

2.1.3 Procedure. The stimulus set was divided into two subsets. Each subset contained half of the exemplars from each category and subcategory (plus or minus one for odd numbers). Each group of subjects saw either the original or the mirror image of each exemplar of one subset in a random order. As a consequence, the same subset was presented to two groups. However, the order of presentation and the image used from each exemplar were counterbalanced. Subjects were requested to write down the name that describes best the presented object or animal. Each student received several sheets with the rank numbers of the drawings.

The line drawings were presented on a large white screen $(6 \mathrm{~m} \times 2.5 \mathrm{~m})$ at the front of an auditorium with a BARCO projector connected to a personal computer with a 486 processor. Each image was shown for $4 \mathrm{~s}$, preceded and followed by a brief visual message with the rank number of the image $(1750 \mathrm{~ms}$ each). The first presentation of the rank number of the subsequent image was preceded by a blank screen $(500 \mathrm{~ms})$ and a tone to warn subjects that they had to look up.

2.1.4 Analysis. Traditionally, names at a more specific level than the most commonly used name are collapsed into one percentage to represent the nameability and concept agreement of a stimulus (eg Snodgrass and Vanderwart 1980). However, for the present purposes we needed to have information on the number of times a stimulus is named at a more specific level.

We calculated four percentages for each stimulus. First, the name percentage represents how many times the most common answer was given literally. In the table of Appendix B, we give the most appropriate English translation of this most common answer in Dutch.

Second, the concept percentage represents the relative number of answers at the same level of abstraction and more or less the same meaning ('equivalent answers'). We used the following rules in the scoring of this percentage:

- We treated some names as equivalent that are not synonyms (according to the Dutch standard dictionary 'Van Dale', see Geerts and Heestermans 1989) because the subjects did not seem to make any difference between them. Normatively, these names were often more specific than the most common name (but they always fitted with that name). However, if a subject used such a name, then he/she applied 
it to all the category members. Most of these intersubject differences reflected the subjects' different dialects.

- A diminutive of the most common answer or one of the equivalent answers was treated as equivalent. For example, 'small ship' was considered to be equivalent to 'boat'.

- If a subject gave more than one answer to one stimulus, then the answer was counted as equivalent if both answers were correct and one answer was the most common answer. If one of these answers was wrong (defined as not included in the concept of the most common name), then the answer was treated as incorrect, except if the correct name was more specific than the wrong answer (eg 'fish/ dolphin' as answer to a picture of a 'dolphin').

Third, the subordinate percentage represents the relative number of times a name was given that was more specific than the most common name. A name was included as subordinate when several subjects used this name to represent differences between the exemplars.

Finally, the identification percentage represents how many times the most common name, equivalent names, and subordinate names were used. However, if the sum of these three categories for another name than the most common name exceeded the same sum for the most common name, then the identification percentage is given for that other name. For example, for stimulus 144 'rat' was the most common name given by $27 \%$ of the subjects. Almost no other names were equivalent or subordinate to 'rat', resulting in an identification percentage of $28 \%$. However, if we sum all names that were equivalent and subordinate to the term 'rodent', then we find a much higher identification percentage (98\%), which is the percentage that is shown in Appendix B. This dissociation between the names used for both percentages was found for two categories in particular- 'mouse' and 'dolphin'.

\subsection{Results}

The results are given in Appendix B. We eliminated all the answers of the thirteen subjects $(3.5 \%)$ who had confused several rank numbers. We give the most appropriate English translation of the names that were given by our Dutch-speaking subjects. There is no reason to suspect that the relevant percentages would differ substantially between our subjects and English or American people. A normative study with the stimuli from Snodgrass and Vanderwart (1980) with Dutch subjects (Van Schagen et al 1983) found only significant differences on the relevant percentages for some culturally biased concepts like 'baseball bat'. We included object categories without any obvious cultural variation between most Western countries. Of course, the number of alternative names that refer to the same concept (called 'equivalent' names in section 2.1.4) could differ substantially between languages, which is the reason why we do not capture this variable into a percentage.

The results for the two groups of subjects who received the same exemplars (in one of the two mirror image versions) are summed. No consistent effects of the presentation order of the stimuli were found. The subordinate percentage was not different if a stimulus was the first shown exemplar of a category or the last.

\subsection{Discussion}

For a number of categories there is a high agreement in names and percentages between the exemplars (eg 'bird'), while the opposite is found for other categories (eg 'glass'). In line with our expectations, we found that line drawings do not permit a differentiation of the categories 'mouse' and 'dolphin' from the more general categories 'rodent' and 'fish', respectively. Many subjects named mice as rats or other rodents, and dolphins as fish. In the biological taxonomy, 'fish' is not a superordinate category for 'dolphin', but many subjects give this label as an alternative. For these categories, 
form information per se is insufficient for accurate object identification, not only at a subordinate level, but also in differentiating categories that hardly anyone would collapse on the basis of additional information.

These findings contrast with the clear distinction that is made between the categories 'bird' and 'chicken', even if the analysis is constrained to the first 'chicken' or 'bird' image shown to a group of subjects. Compared with this effect, there is only a minor difference in level of naming between exemplars in most other categories. The category 'glass' displays most variability. Several exemplars are named often at a more specific level. One stimulus (number 4), is named most often at such specific level. However, even for this exceptional case, nearly half of the subjects named the stimulus at the category level, whereas only a few subjects named a 'chicken' at the level of 'bird'. This confirms that most other categories in our stimulus set contain rather typical exemplars.

The calibrated stimulus set has all properties listed in section 1 . First, the use of simple line drawings ensures that only shape information determines naming differences between the stimuli. Second, we minimised the existence of salient subordinate labels, which is illustrated by the contrast between the relatively low intracategory variability in the level of naming within all categories and the clear differentiation between 'chicken' and 'bird'. Third, in contrast to other calibrated stimulus sets (eg Snodgrass and Vanderwart 1980), our stimulus set contains a number of different exemplars of several basic-level categories. Fourth, the stimulus set covers a wide range of objects, including both natural and man-made objects. This makes the set suitable for investigating effects that should be found across a wide range of objects, as well as for comparing specific characteristics of particular object categories. Fifth, we calibrated the proportion of names given at two different levels of abstraction, which is necessary if one wants to use the stimulus set for studying the identification and recognition of objects across several levels of abstraction.

\section{Experiment 2: Validity of the proportion of subordinate names}

The stimulus set was designed to contain typical exemplars from each category. However, in several categories we also found substantial differences for the subordinate percentage between exemplars from the same category. For example, most exemplars in the category 'horse' are named almost always at the category level. However, a finer differentiation is made for the exemplars with a heavier anatomy. Such differences in the frequency of naming at a particular level have been used by Jolicoeur et al (1984) to demonstrate that atypical exemplars from basic-level categories have their entry point on a more subordinate level. In experiment 2, we investigated the validity of such differences in naming as a measure of the typicality of an exemplar in our stimulus set. Whereas part of the effect in the study of Jolicoeur et al (1984) could be mediated by the existence of salient subordinate names (like 'chicken'), such names are not that apparent in our study. As an illustration, we can again point to the finding that no 'horse' stimulus is named more than half of the time with a subordinate name, whereas all 'chicken' stimuli are named consistently with their salient subordinate name. Most subjects used the same word to denote the 'chicken' stimuli, whereas the differentiation in the category 'horse' was made by a high variability of adjectives.

It is important to note that the design of this experiment (and experiment 3) includes the frequency of naming at a particular level as the independent variable and typicality as the dependent variable. We want to show only the relationship between the two variables (experiment 2), and to use it to determine the effect of other manipulations (experiment 3). Probably, the actual causal relation is the other way around: the typicality of exemplars is the basis for the differences in naming frequencies. 


\subsection{Method}

3.1.1 Subjects. Twelve undergraduate students participated in this study for course credits. They completed the experiment in four groups ranging from two to four persons.

3.1.2 Stimuli. 32 stimuli were selected from the complete stimulus set following three rules. First, only the categories with a high variability in the subordinate percentage were included. Second, these categories had to contain 4 exemplars with relatively large differences in this percentage ( 2 exemplars with a small and 2 with a substantially larger subordinate percentage). Third, only stimuli with a high identification percentage were included. We selected 4 exemplars from 8 categories and assigned them to 2 conditions. The basic-level condition contained the 2 exemplars from each category with a small subordinate percentage, while the subordinate condition consisted of the exemplars with a larger subordinate percentage. There was no significant difference between the two conditions in identification percentage $(99.13 \%$ and $99.44 \%$, respectively). The ratio of the subordinate percentage and the concept percentage is shown in table 1 for the stimuli of both conditions.

Table 1. The stimuli from experiments 2 and 3 for each condition with their ratio of subordinate percentage $(S)$ and concept percentage $(C)$. Stimulus numbers refer to the numbers in the appendices.

\begin{tabular}{|c|c|c|c|}
\hline \multicolumn{2}{|c|}{ Basic-level condition } & \multicolumn{2}{|c|}{ Subordinate condition } \\
\hline stimulus & proportion $(S / C)$ & stimulus & proportion $(S / C)$ \\
\hline 3 & 0.0357 & 5 & 0.6793 \\
\hline 9 & 0.0305 & 8 & 0.9346 \\
\hline 47 & 0.0230 & 45 & 0.4436 \\
\hline 54 & 0.0113 & 49 & 0.2534 \\
\hline 56 & 0.0848 & 62 & 0.2898 \\
\hline 65 & 0.0783 & 63 & 0.6036 \\
\hline 103 & 0.0484 & 101 & 0.5214 \\
\hline 108 & 0.0290 & 111 & 0.6448 \\
\hline 112 & 0.0592 & 115 & 0.3587 \\
\hline 121 & 0.0659 & 118 & 0.9668 \\
\hline $128 *$ & 0.0287 & $123 *$ & 0.1401 \\
\hline $129 *$ & 0.0659 & $127 *$ & 0.3768 \\
\hline 176 & 0.0596 & 177 & 0.7724 \\
\hline 183 & 0.0530 & 178 & 0.5214 \\
\hline 187 & 0.0113 & 188 & 0.4833 \\
\hline 197 & 0.0173 & 193 & 0.2963 \\
\hline 218 & 0.0057 & 212 & 0.4146 \\
\hline 219 & 0.0000 & 213 & 0.3111 \\
\hline
\end{tabular}

* These stimuli were used only in experiment 3 .

3.1.3 Material. Stimuli (with sizes between 5 and $8 \mathrm{deg}$ ) were presented on a 17-inch monitor (background luminance: $20 \mathrm{~cd} \mathrm{~m}^{-2}$ ).

3.1.4 Procedure. All subjects in a group were seated next to each other in front of the monitor. Stimuli were presented sequentially for $4000 \mathrm{~ms}$ each with a $1500 \mathrm{~ms}$ interstimulus interval in a random order. Subjects received a sheet with 32 names, each with a 7 -point scale $(1=$ not typical; $7=$ typical $)$. The name was always the most common name from the category to which the exemplar belonged. Subjects were requested to indicate how typical the exemplar was for the category name. Stimuli were presented one time before the actual experiment (but after the instructions) to give the subjects an idea of the variability in typicality in the stimulus set (they were encouraged to use the whole scale). 


\subsection{Results}

The data were analysed in different ways. First, we tested the hypothesis that the typicality in the subordinate condition would be larger than in the basic-level condition. This onesided hypothesis could be rejected $\left[t_{11}=5.29, p<0.001\right.$ (mean typicality 3.8 and 4.7, respectively)].

The Pearson correlation between the mean of the typicality ratings per stimulus and the ratio of the subordinate and concept percentage was also significant $\left(r_{32}=-0.39, p<0.05\right)$.

\subsection{Discussion}

The results show that the subordinate percentage partly reflects the typicality of a stimulus for the basic-level category, even in a stimulus set with relatively small variations in naming frequencies at distinct levels of abstraction between the stimuli. The relationship between both variables holds also for stimuli without salient subordinate names.

\section{Experiment 3: The effect of degrading images on typicality}

In experiment 3, we presented altered versions of the stimuli to investigate whether, and to what extent, these images still contain information regarding the typicality of objects. In addition to the original line drawings, two other versions of the images were used: black silhouettes and degraded images without detailed visual information about the object's internal features (see figure 2). A study by Johnson and Mervis (1997) indicated that normal subjects (ie non-experts) have difficulties with extracting enough information from silhouettes to make a subordinate categorisation. We will study whether subjects can differentiate silhouettes of objects within basic-level categories according to their category typicality to the same extent as more detailed line drawings of these objects. Additionally, we used degraded images that, compared to silhouettes, contained more information regarding the inner structure of the objects but less specific contour information. However, compared with normal line drawings, these degraded images have lost most information regarding specific details (ie it would become very difficult to identify the object if given only part of the degraded image). As a consequence, the results with this third image type were intended to show us how much information about the inner conceptual structure of categories (Rosch 1973) can still be recovered from the global visual structure of their exemplars.
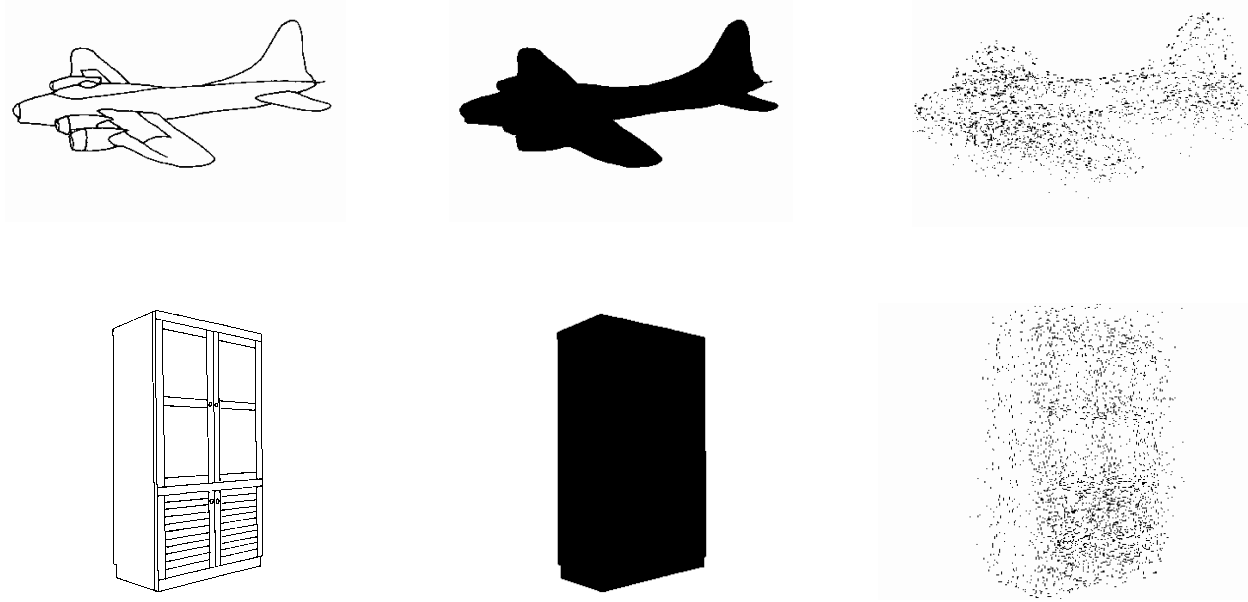

Figure 2. The three presentation modes of 2 exemplars (stimuli 56 and 112) as used in experiment 3: (from left to right) original line drawing, silhouette version, and degraded image. 
4.1 Method

4.1.1 Subjects. All thirty-six subjects were undergraduate students of the University of Leuven and participated for course credits. They were tested in nine groups of three to five subjects.

4.1.2 Stimuli. In this experiment, we used the same stimulus set as was used in experiment 2, with addition of 4 exemplars from a ninth category (selected by following the same rules as described in section 3.1.2). The stimuli were presented in three modes (see figure 2): original line drawings, silhouettes, and degraded images. The degraded images were constructed by using an algorithm that divides the images in small rectangles and exchanges their position. Results could differ between different noise paradigms as they affect different kinds of information in the images.

Our algorithm allowed us to choose the size of the rectangles and the city-block distance that they were to be displaced. As a consequence, we could manipulate the extent to which detailed contour information (rectangle size) is lost, independently from the level of degradation (rectangle displacement). We used rectangles with a size of $4 \times 3$ pixels and a spatial shift of 30 pixels. A prior investigation of several combinations of picture size and spatial shifting showed us that the level of degradation was not directly affected by absolute spatial shift, but rather by spatial shift relative to the stimulus size (a spatial shift of, for example, 10 pixels had less impact on large pictures than on small pictures). To compare the level of degradation across experiments in which different stimulus sizes were used, we formalised the relative spatial shift as the absolute shift divided by the length of the diagonals of the pictures. The relative spatial shift in the present experiment was $D=0.048$, which is comparable to the relative spatial shift $D=0.0431$ used by Op de Beeck et al (2000). The size of the original stimuli $(800 \times 600$ pixels $)$ was reduced to $500 \times 375$ pixels because of limitations of the algorithm for degradation. No important details seemed to be lost by this size reduction. In other experiments (unpublished observations) we found that recognition performance was not affected by even more dramatic size reductions (to $200 \times 150$ pixels). Visual inspection of the data revealed no loss of important details even in this last case.

We assigned the exemplars to a basic-level condition and a subordinate condition based on the subordinate percentage (see experiment 2). Stimuli were randomly assigned to one of three groups of 12 stimuli with the restriction that each group should contain an equal number of exemplars from each condition. In addition, each group contained minimally 1 and maximally 2 exemplars from each category. All stimuli were presented to each subject in a random order, but each group of stimuli was displayed in another mode (line drawings, degraded images, or silhouettes). Across all subjects, all stimuli were presented an equal number of times in each mode (with a small deviation of 2 related to the unequal number of subjects in the different groups).

4.1.3 Material. Stimuli (with sizes between 4 and $6 \mathrm{deg}$ ) were presented on a 17-inch monitor (background luminance: $20 \mathrm{~cd} \mathrm{~m}^{-2}$ ).

4.1.4 Procedure. The procedure was analogous to the procedure of experiment 2, except for an additional instruction. It was emphasised to the subjects that it was not the purpose of the experiment that a certain mode of presentation was less typical than another. They had to concentrate on the typicality of the original object to which an image referred.

\subsection{Results}

The typicality ratings were analysed with an ANOVA with two within-subject variables: 'entry-point level' (basic level or subordinate) and mode (line drawings, degraded stimuli, or silhouettes). 
The main effect of entry-point level was significant $\left(F_{1,35}=16.88, p<0.001\right)$. The main effect of mode was also significant $\left(F_{2,70}=16.55, p<0.001\right)$, indicating that the typicality ratings of the subjects were influenced by the mode of presentation, despite our explicit instruction to ignore it. The interaction between entry-point level and mode did not reach significance $\left(F_{2,70}=2.07, p=0.13\right)$ (see table 2). The simple main effect of entry-point level was significant for line drawings $\left(F_{1,70}=21.94\right.$, $p<0.001)$, and for degraded images $\left(F_{1,70}=17.72, p<0.001\right)$, but not for silhouettes $\left(F_{1,70}=1.30, p>0.26\right)$.

Table 2. Mean typicality ratings for stimuli with a high or low subordinate percentage (subordinate and basic-level condition, respectively) for each presentation mode (line drawings, silhouettes, and degraded images).

Level Line drawings Silhouettes Degraded images

\begin{tabular}{llll}
\hline Basic level & 5.2 & 4.2 & 4.2 \\
Subordinate level & 4.5 & 4.0 & 3.6
\end{tabular}

\subsection{Discussion}

The relationship between level of naming and typicality as found in the previous experiment was clearly confirmed. Additionally, this relationship was found to be robust for a degradation of the pictures. Apparently, subjects were capable of extracting information from the degraded pictures regarding the differences between exemplars from the same category. Our results do not support that this information can also be extracted from silhouettes, confirming the result of Johnson and Mervis (1997) that unexperienced subjects are unable to categorise silhouettes of songbirds at the subordinate level.

These results show that the visual system is able to cope with some attenuations of information in the input, but not with all. Which information is preserved in the degraded images and not in the silhouettes? The overall contour is preserved better in the silhouettes. However, some information regarding the 3-D configuration of stimuli is lost. Alternatively, the degradation destroys most of the detailed information about both the contour and the internal features. For example, it seems possible to identify the degraded ear of a 'horse' as such only because it is still presented in the configuration of 'horse'. The most plausible conclusion seems to be that the presentation of the global structure of objects without detailed visual information regarding the components themselves can be sufficient to categorise objects at a subordinate level. It would require further research to determine exactly how the global structure can be derived when no detailed feature information is available.

Most subjects noted afterwards that they had difficulties in identifying the basiclevel category of some degraded images when they had not read their name before seeing the picture the first time (ie before the actual typicality rating). Nevertheless, they were able to differentiate exemplars within categories according to their typicality from these degraded images. This finding suggests that pictures that do not contain enough information to allow reliable basic-level identification in an unconstrained context (ie when no corresponding name had been read) can contain enough information to allow reliable subordinate level differentiation in a constrained context (ie when the category membership is known).

\section{Conclusion}

Our first aim was to develop a stimulus set that can be used to determine the perceptual information that is used to categorise objects at different levels of abstraction. It may also turn out to be useful for other types of categorisation research with pictures as 
stimuli instead of words. Our dependent variable in experiment 1 , the level of naming, turned out to be a valid measure of the typicality of the objects (experiment 2).

In experiment 3 we tried to delineate the kind of information that is used by subjects to represent the internal structure of categories (Rosch 1973). Whereas such information seems to be difficult to extract from silhouettes, other strong degradations of the details in the input did not result in such poor performance. This result suggests that the global structure of an object also contains information regarding the subordinate differences between stimuli.

Acknowledgements. HO is a research assistant from the Fund for Scientific Research, Flanders (Belgium). The authors would like to thank Toon Sykora for writing the software to degrade and to present the stimuli. Financial support was provided by the Research Program of the Fund for Scientific Research Flanders (G.0130.98) and by the Research Council from the University of Leuven $(\mathrm{OT} / 00 / 07)$ to JW.

\section{References}

Behl-Chadha G, 1996 "Basic-level and superordinate-like categorical representations in early infancy" Cognition $60105-141$

Brodie E E, Wallace A M, Sharrat B, 1991 "Effect of surface characteristics and style of production on naming and verification of pictorial stimuli" American Journal of Psychology 104 517-545

Farah M J, Levinson K L, Klein K L, 1995 "Face perception and within-category discrimination in prosopagnosia" Neuropsychologia $33661-674$

Gauthier I, Anderson A W, Tarr M J, Skudlarski P, Gore J C, 1996 "Levels of categorization in visual object recognition studied with functional MRI" Current Biology $7645-651$

Geerts G, Heestermans H (Eds), 1989 Van Dale: Groot woordenboek der Nederlandse taal [Comprehensive dictionary of the Dutch language] (11th revised edition) (Antwerp, Belgium: Van Dale Lexicografie)

Johnson K E, Mervis C B, 1997 "Effects of varying levels of expertise on the basic level of categorization" Journal of Experimental Psychology: General 126248 -277

Jolicoeur P, Gluck M A, Kosslyn S M, 1984 "Pictures and names: Making the connection" Cognitive Psychology $16243-275$

Joseph J E, Proffitt D R, 1996 "Semantic versus perceptual influences of color in object recognition" Journal of Experimental Psychology: Learning, Memory, and Cognition 22 407-429

Markman E M, 1989 Categorization and Naming in Children: Problems of Induction (Cambridge, MA: MIT Press)

Marsolek C J, 1999 "Dissociable neural subsystems underlie abstract and specific object recognition" Psychological Science $10111-118$

Op de Beeck H, Béatse E, Wagemans J, Sunaert S, Van Hecke P, 2000 "The representation of shape in the context of visual object categorization tasks" NeuroImage $1228-40$

Rosch E, 1973 "On the internal structure of perceptual and semantic categories", in Cognitive Development and the Acquisition of Language Ed.T E Moore (New York: Academic Press) pp $111-144$

Rosch E, Mervis C B, Gray W D, Johnson D M, Boyes-Braem P, 1976 "Basic objects in natural categories" Cognitive Psychology $8382-439$

Snodgrass J G, Vanderwart M, 1980 "A standardized set of 260 pictures: Norms for name agreement, image agreement, familiarity, and visual complexity" Journal of Experimental Psychology: Human Learning and Memory 6 174-215

Van Schagen I, Tamsma N, Bruggemann F, Jackson J L, Michon J A, 1983 "Namen en normen voor plaatjes [Names and norms for pictures]" Nederlands Tijdschrift voor de Psychologie $38236-241$

Wasserman E A, Astley S L, 1994 "A behavioral analysis of concepts: Its application to pigeons and children", in The Psychology of Learning and Motivation volume 31 Advances in Research and Theory Ed. D L Medin (San Diego, CA: Academic Press) pp 73-132

\section{APPENDIX A: Stimulus set}

This appendix shows one image of all exemplars in the stimulus set. All exemplars of the same category are grouped and categories are displayed in the order of figure 1. These stimuli are available in electronic format with no charge (see http://www.psy.kuleuven.ac.be/ 

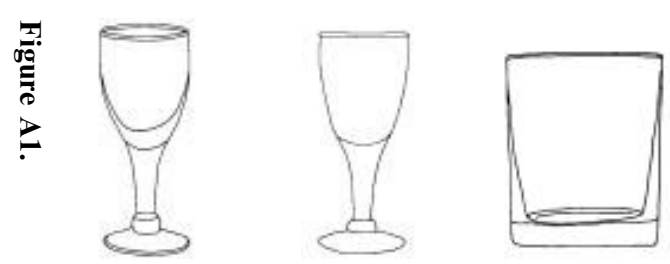

3.

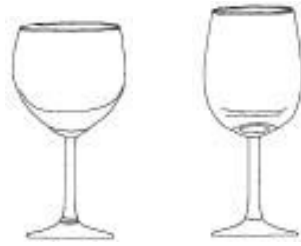

4.

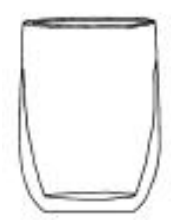

6.

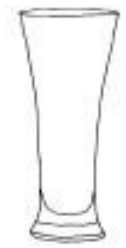

7.

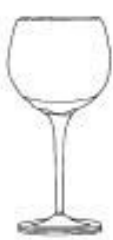

8.

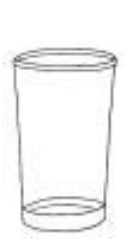

9.

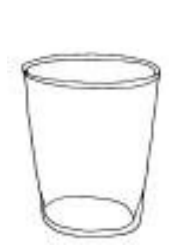

10.

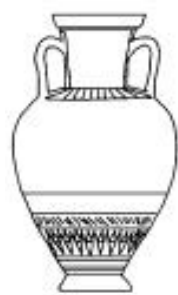

11.

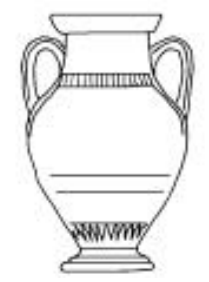

12.

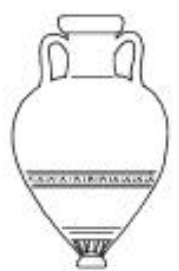

13.

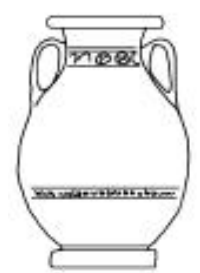

14.

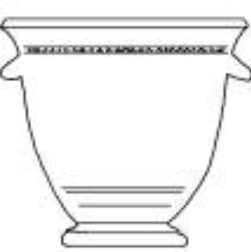

20.

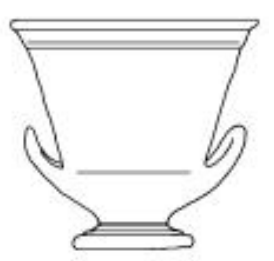

21.

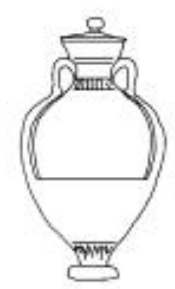

15.

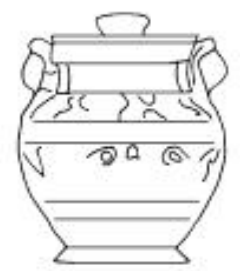

16.

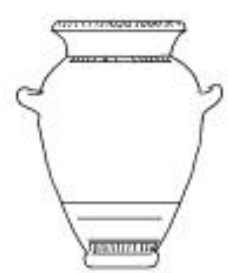

17.

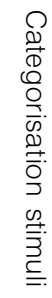

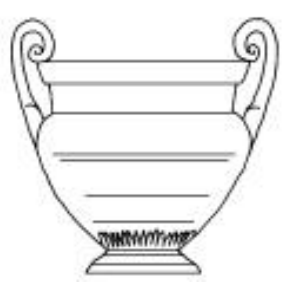

19.

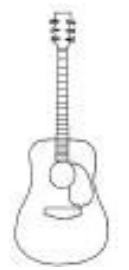

22.

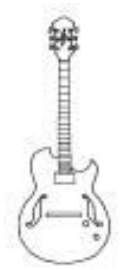

23.

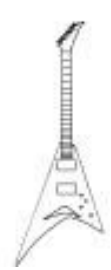

24.

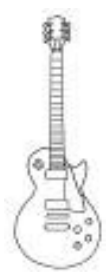

28.

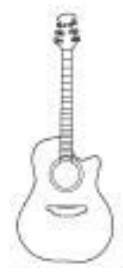

29.

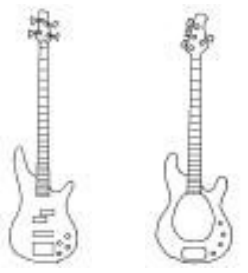

30.

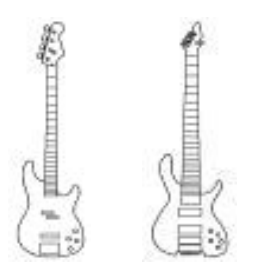

33.

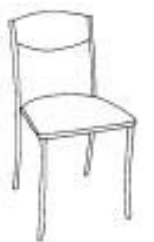

34.

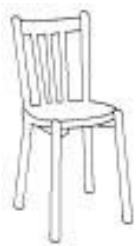

35.

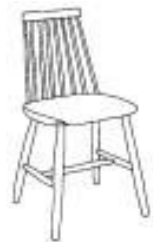

36.

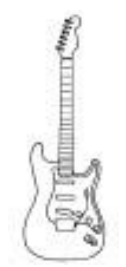

25.

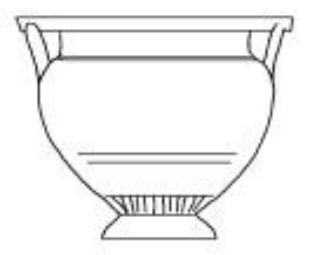

18.

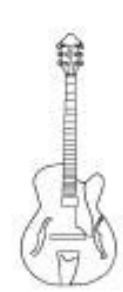

27.

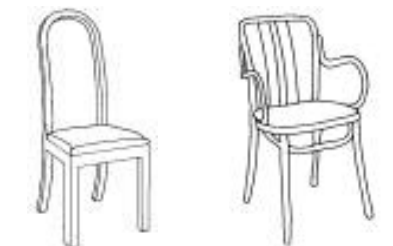

38. 

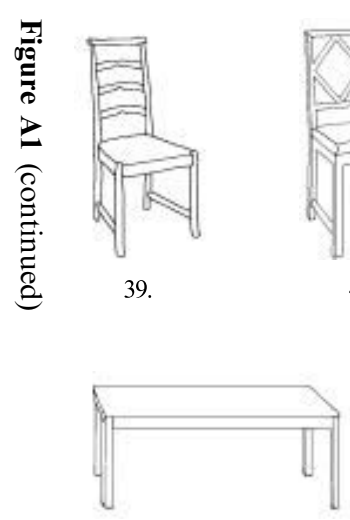

47.

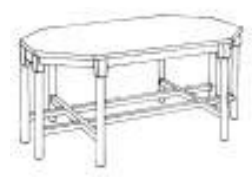

53.

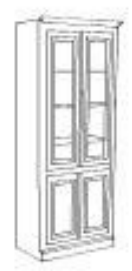

61.

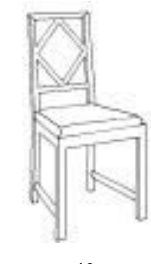

40.

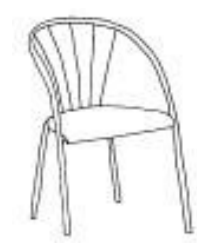

41.

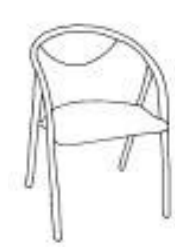

42.

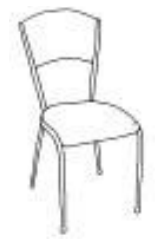

43.
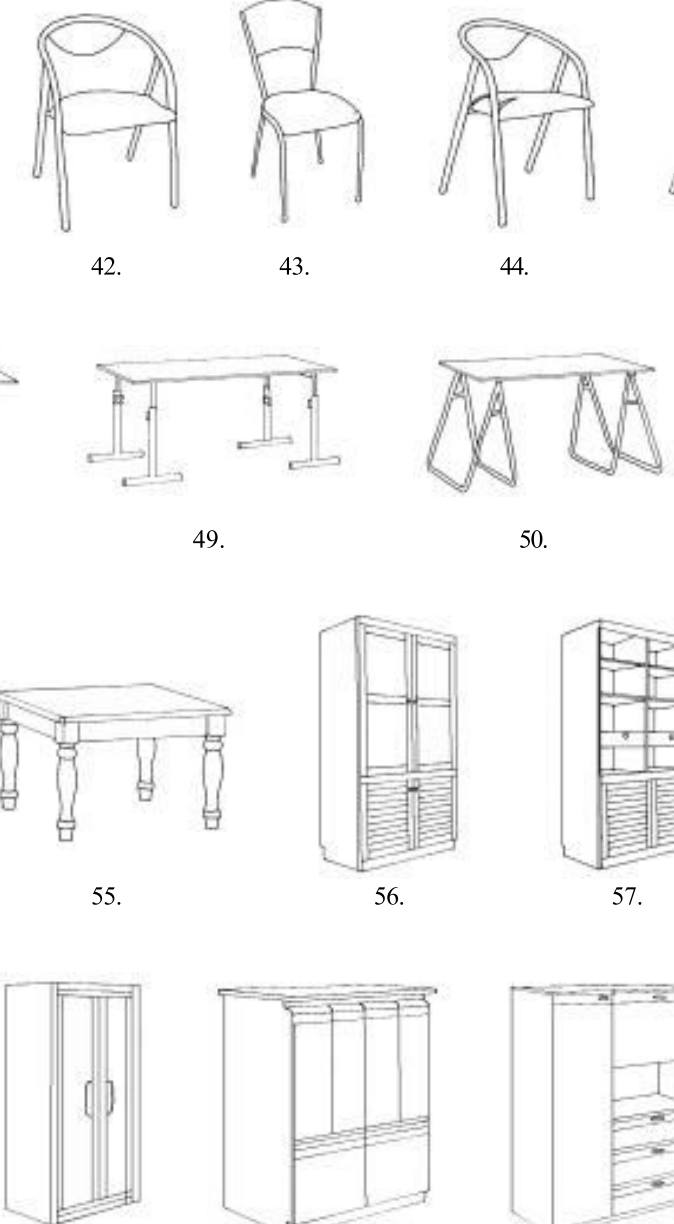

64.
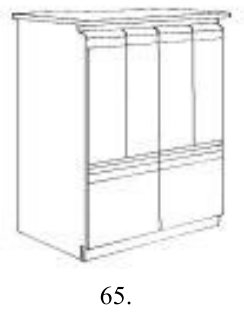

65.
56.

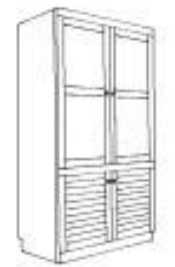

.
44.

50.
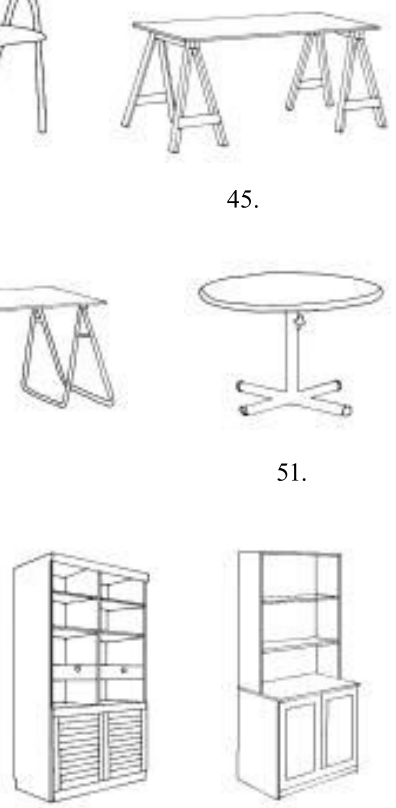

45.

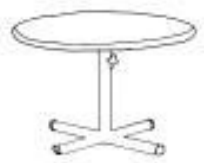

51.

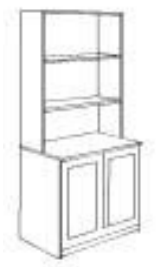

58

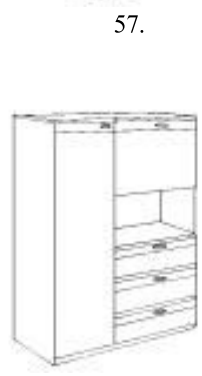

66.

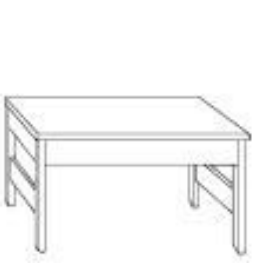

46

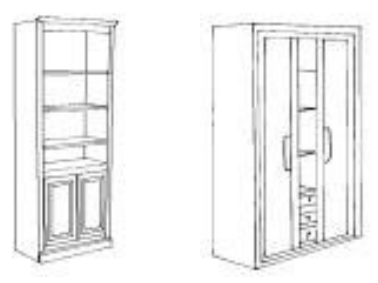

63.

62.

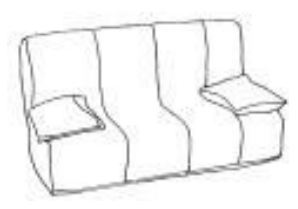

67.

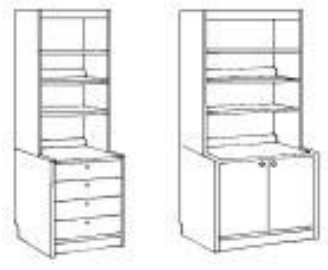

$59 . \quad 60$.

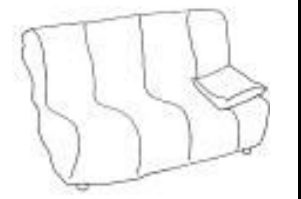

68.

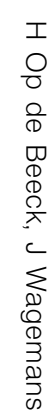




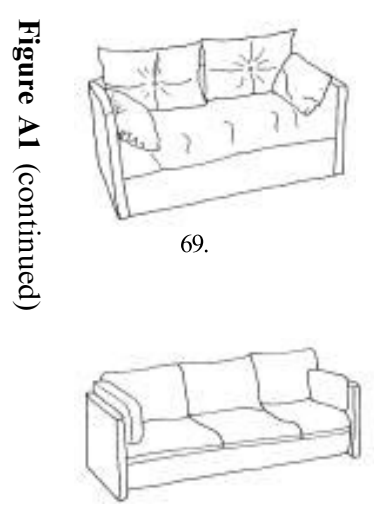

75.

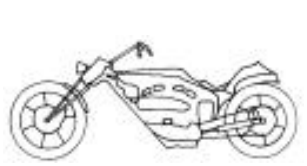

82.

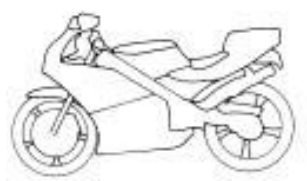

88.

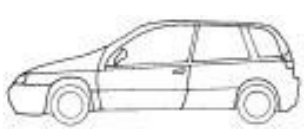

94.

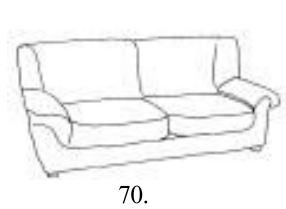

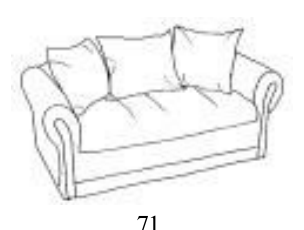

71.

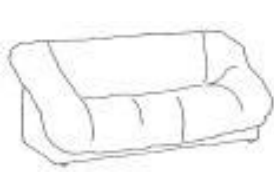

72.

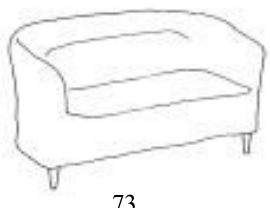

73.
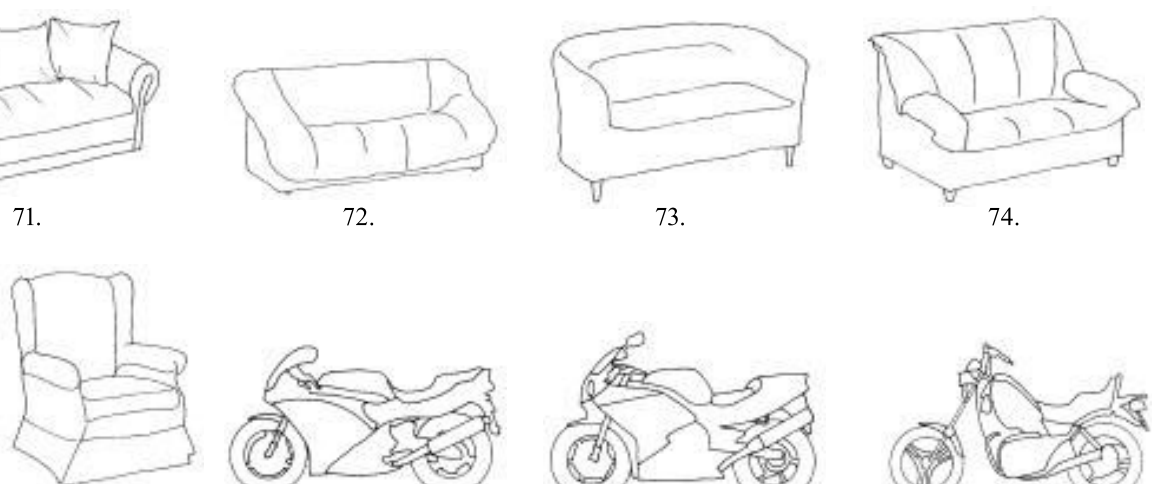

78.

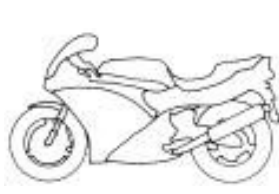

79.

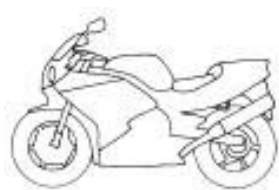

80.

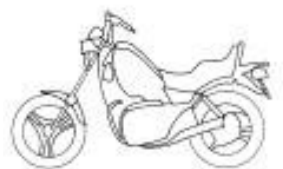

81.

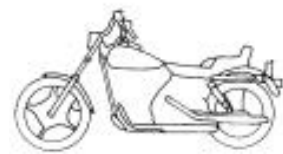

85

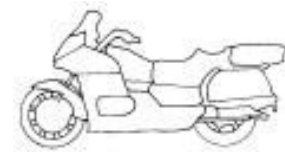

86.

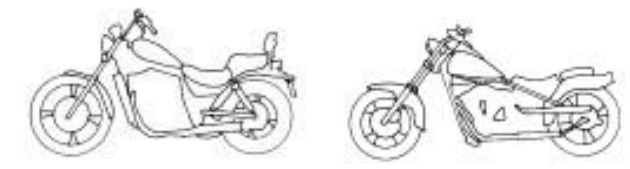

83.
84.

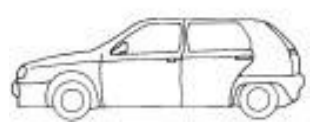

89.

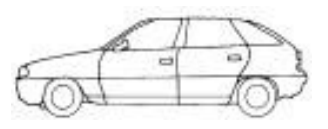

90.

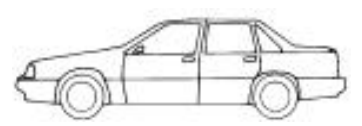

91.

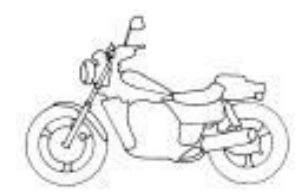

87. 

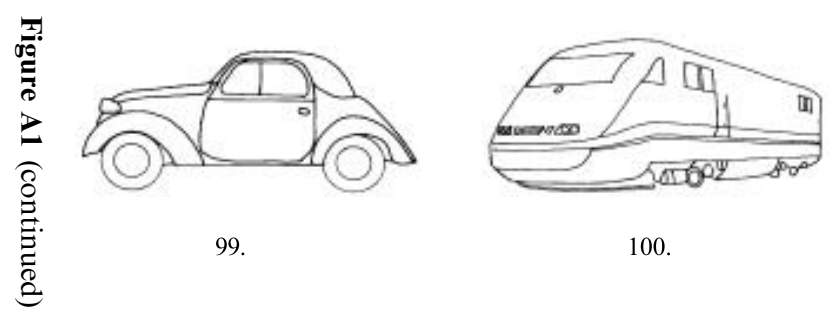

100.

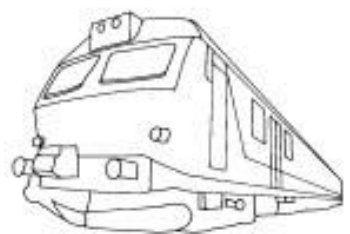

104.

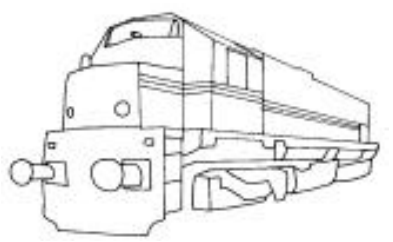

109.

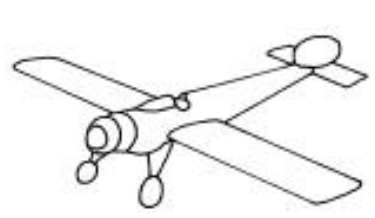

114

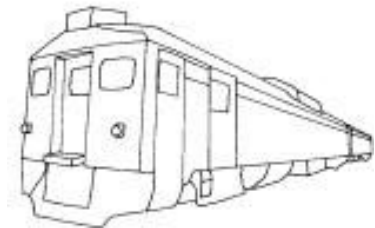

105.

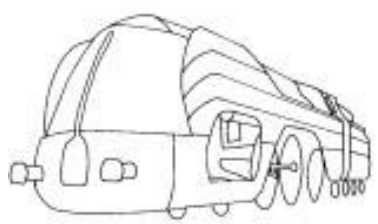

110.

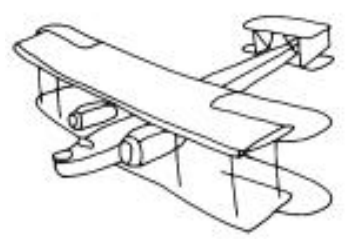

115.

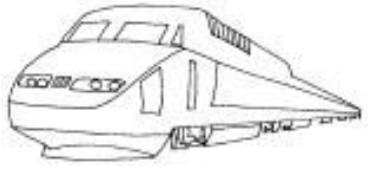

101

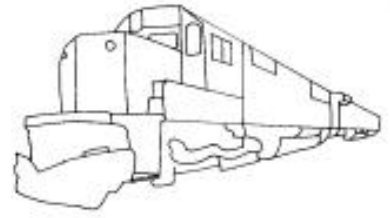

106.

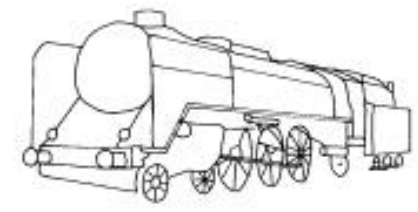

111.

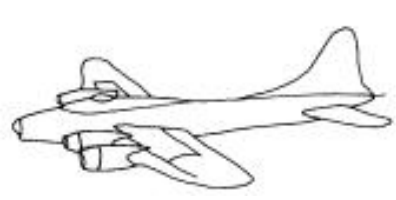

112.

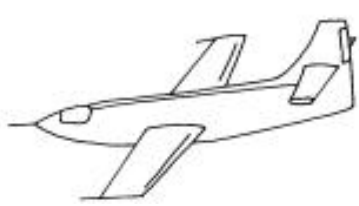

117.

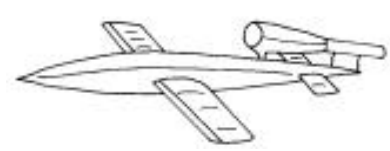

116.

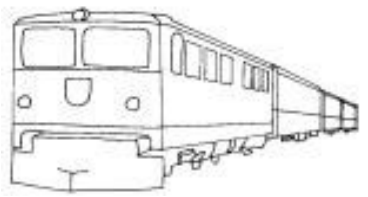

103.

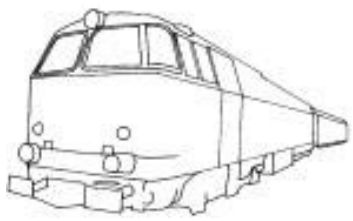

108.

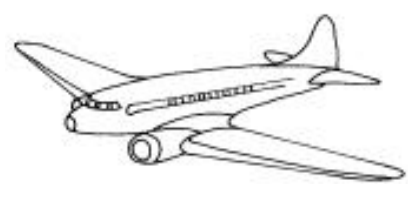

113.

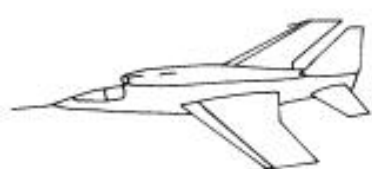

118. 
重

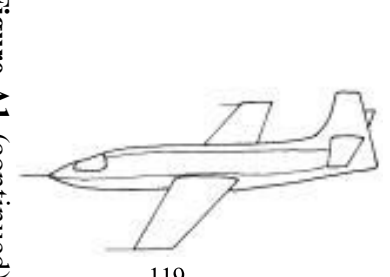

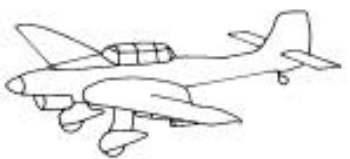

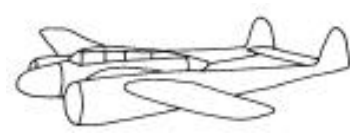

121.
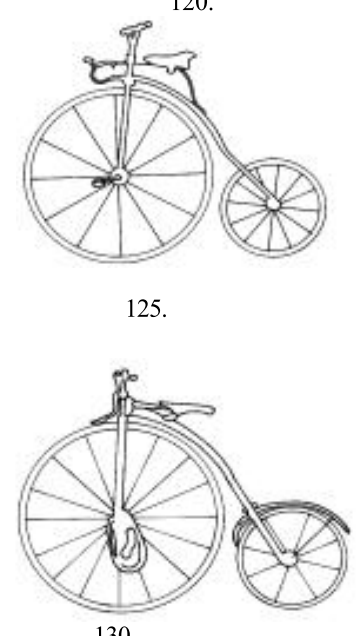

129.
125.

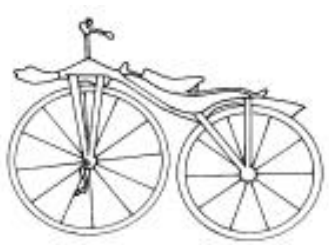

126
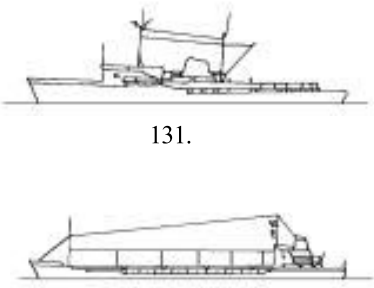

134.

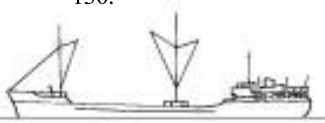

138.

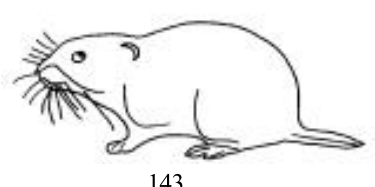

143.

t.

139.

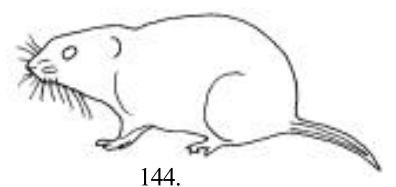

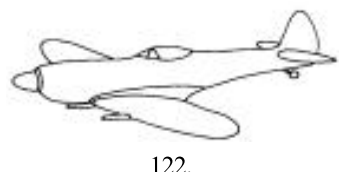

122

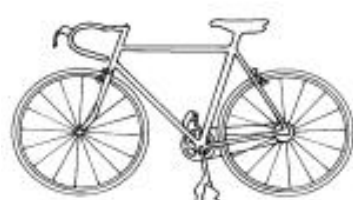

127.
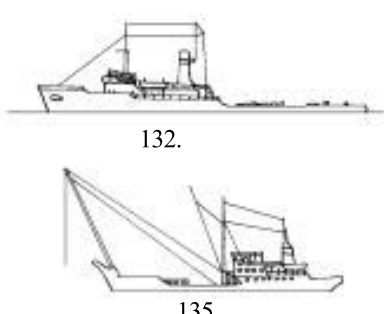

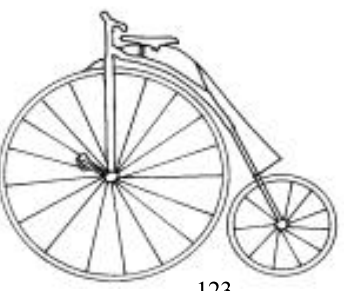

123

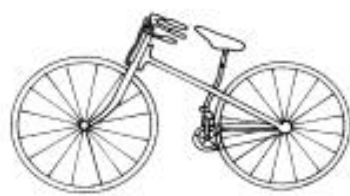

128.

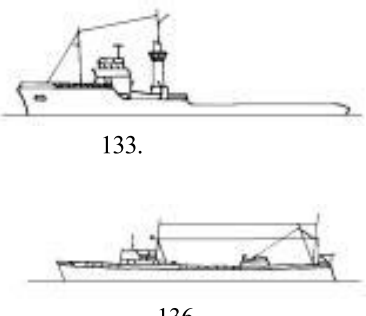

136

Anery

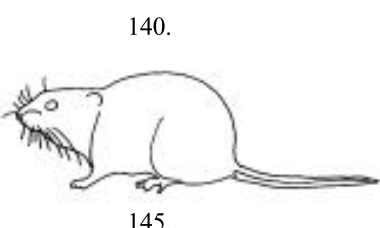




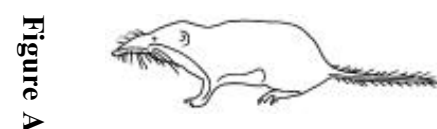

147.

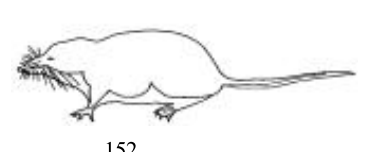

152.

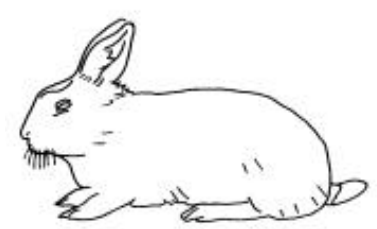

157.

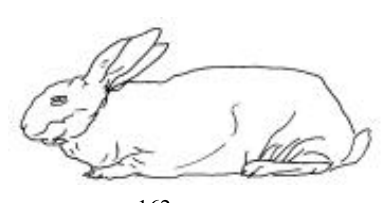

162.

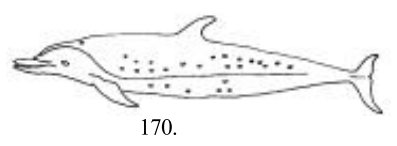

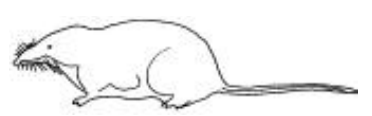

148.

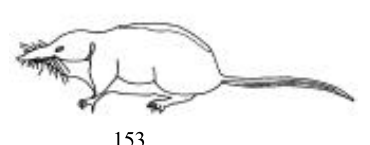

153.

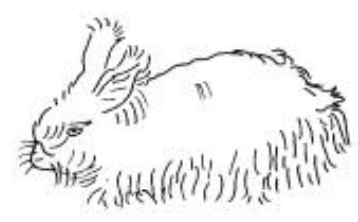

158.

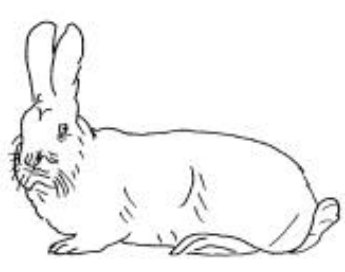

163.

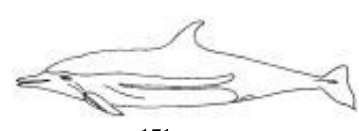

171.

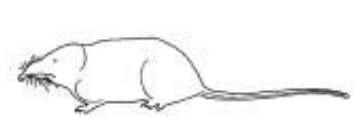

149.

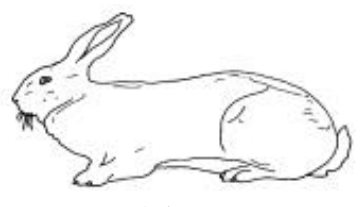

154.

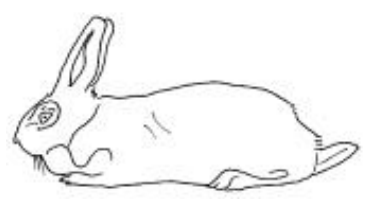

159.
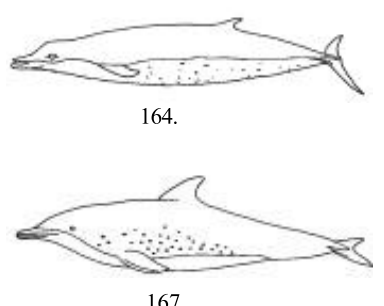

167.

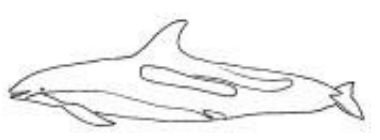

172.

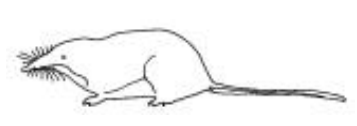

150.

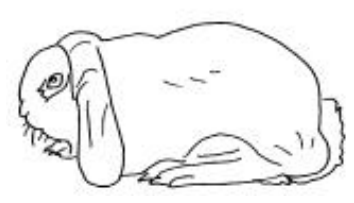

155.

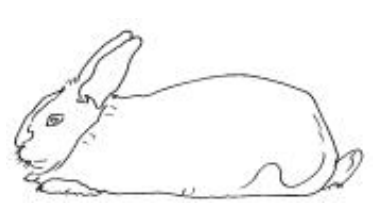

160.
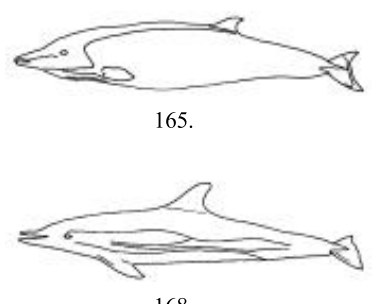

168.

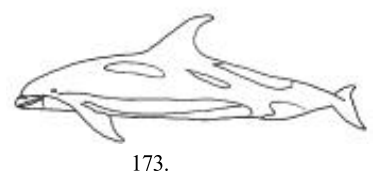

173.
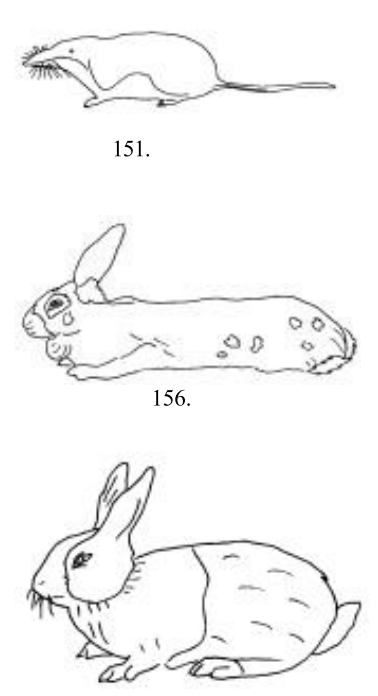

161.
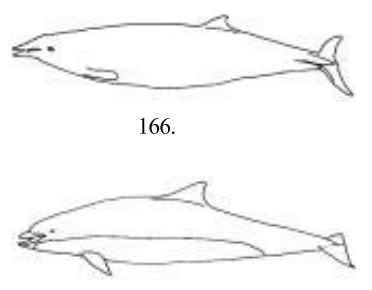

169.

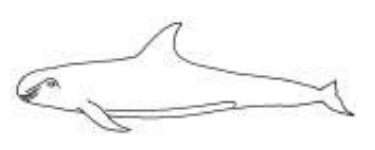

174.

$\vec{\omega}$
N

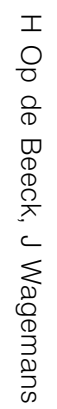



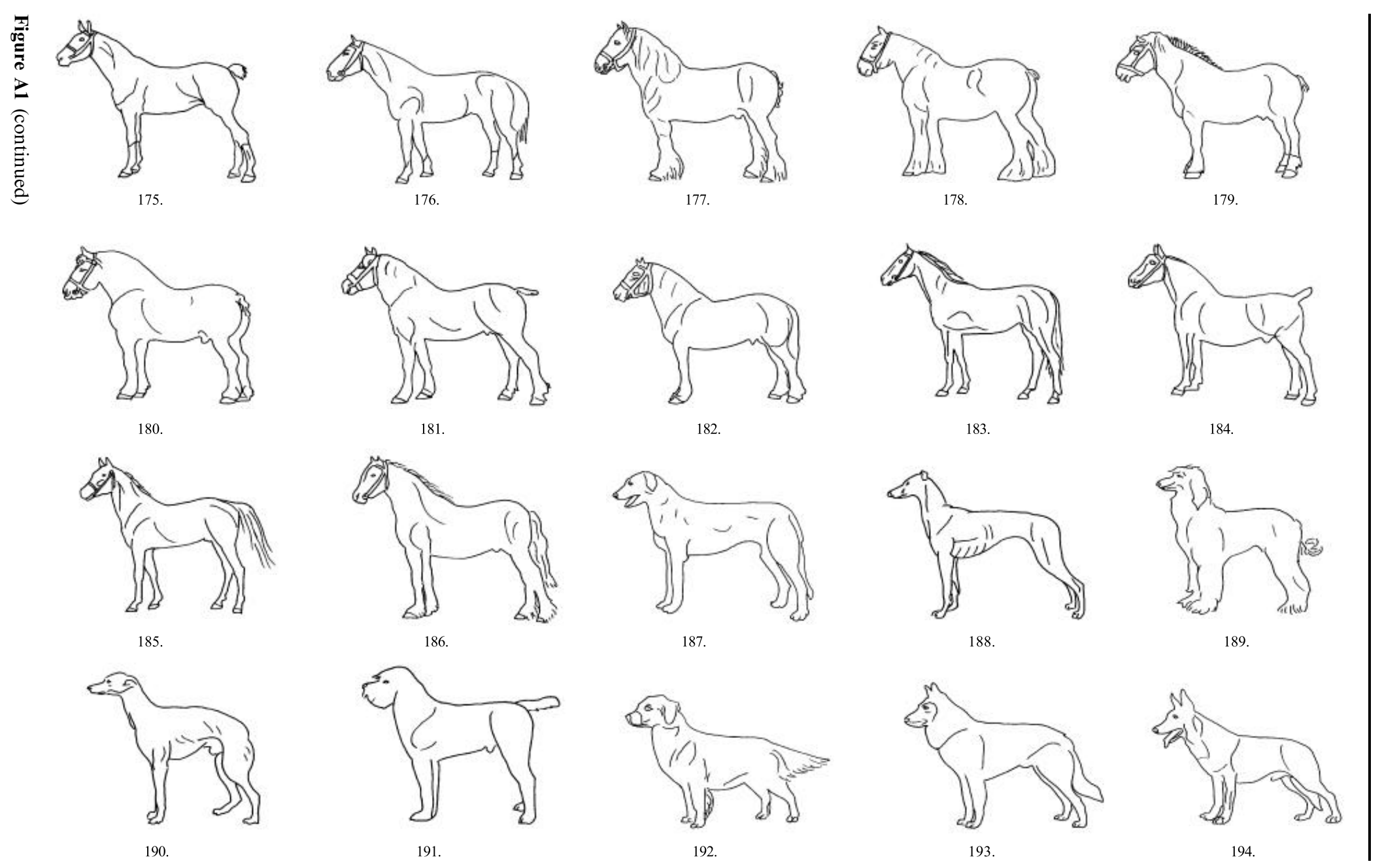

$\vec{\Phi}$ 

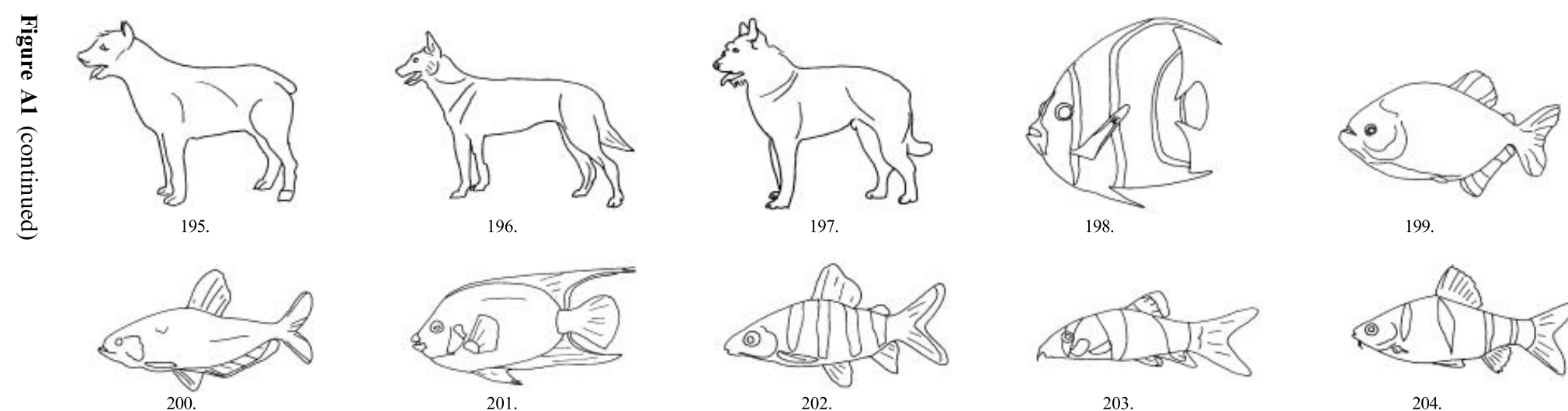

199
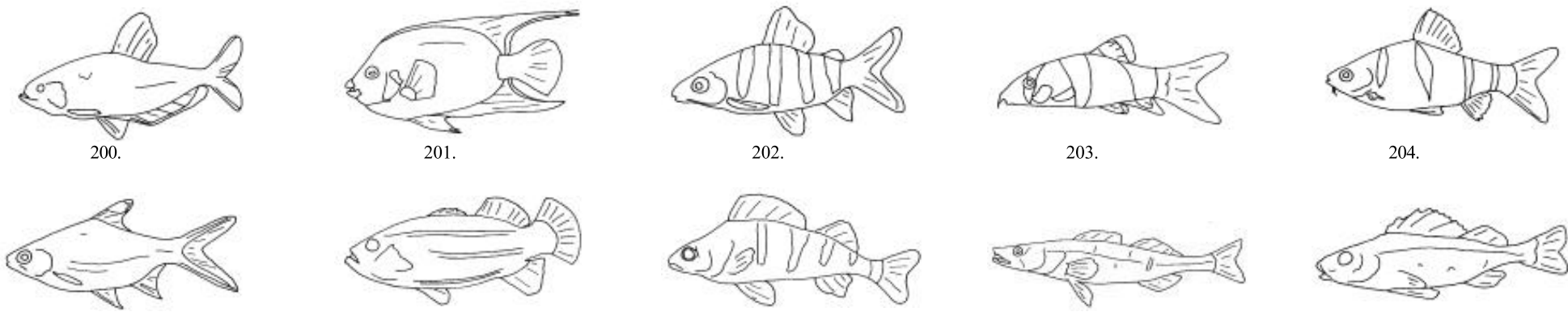

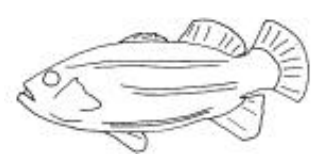

a)

206

207.

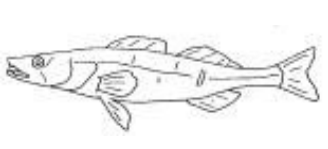

208.

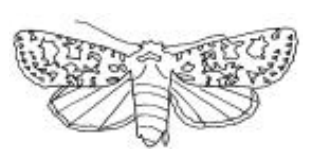

212.

211.

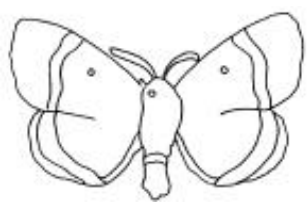

216.

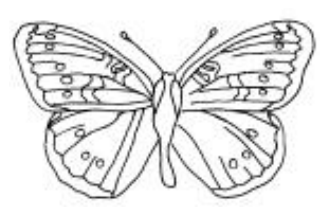

217.

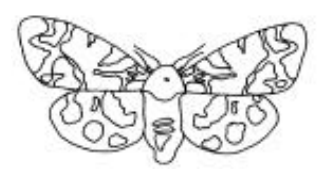

213.

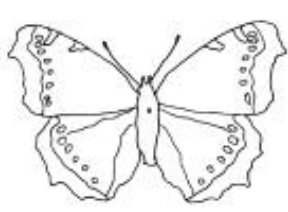

218.
(0) $\frac{523253}{35}$

209.

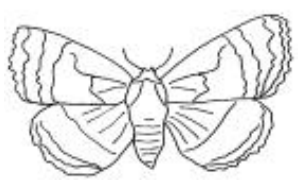

214.

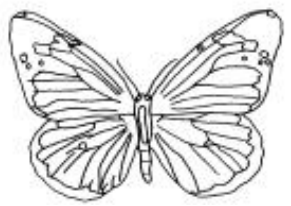

219. 

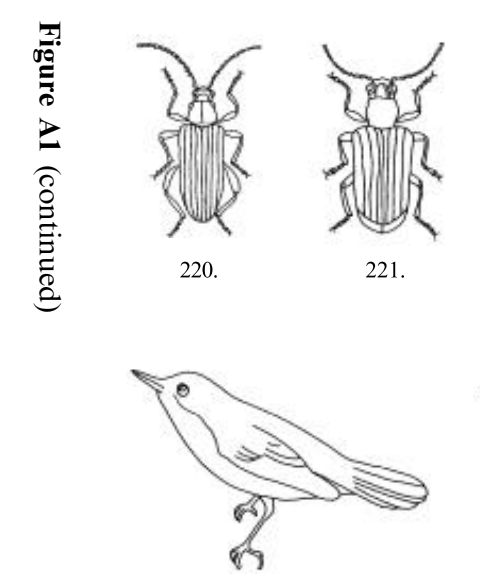

230.

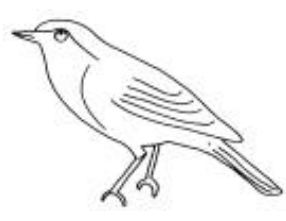

236.

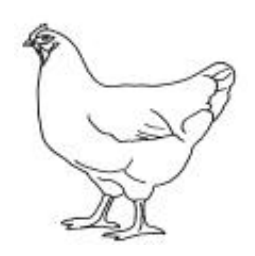

243.
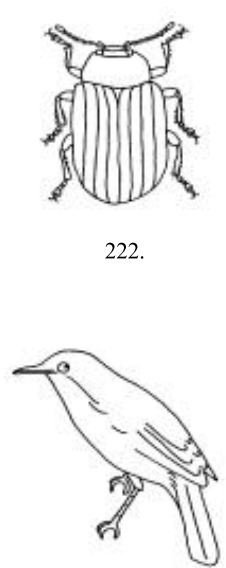

231.

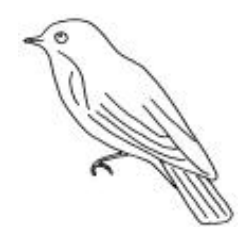

237.

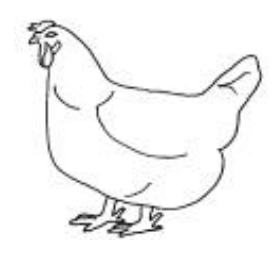

244

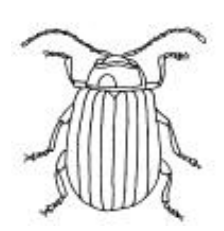

223.

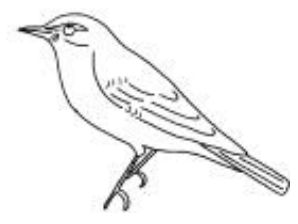

232.

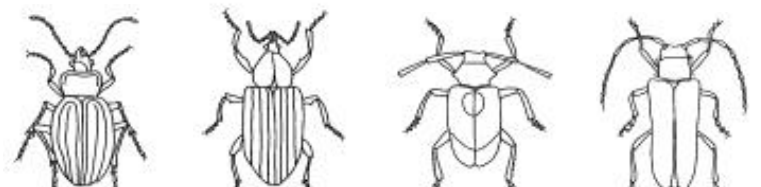

225

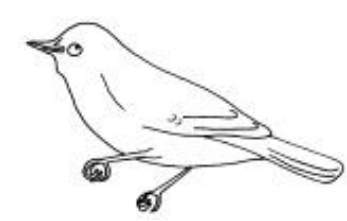

233

234 inp

228.

229
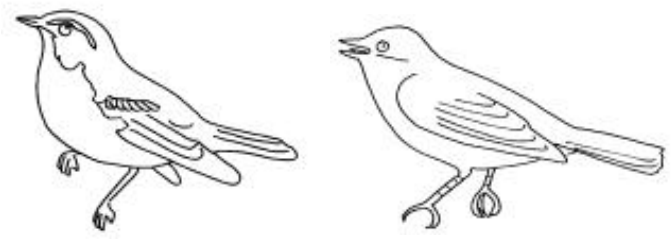

235.

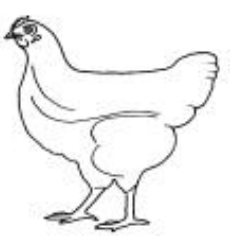

242.

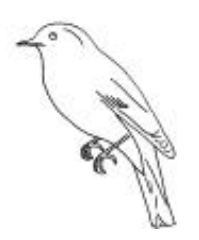

238.

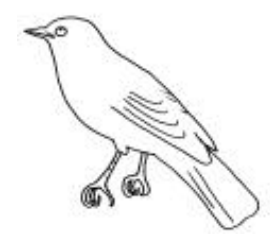

239.

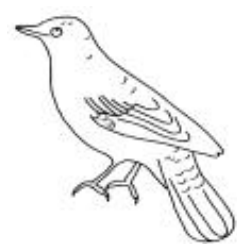

240.

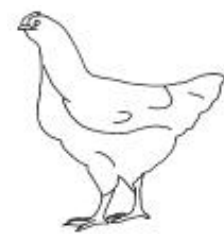

241.

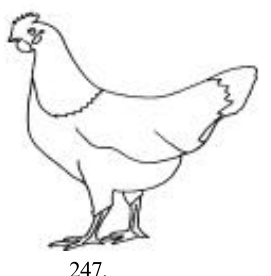

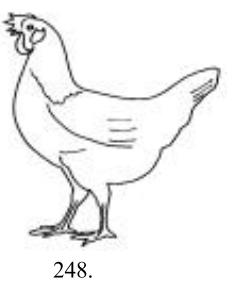




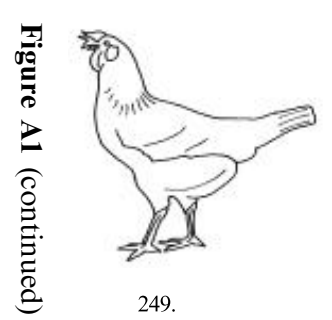

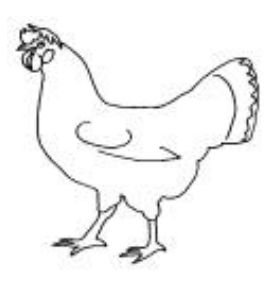

250.

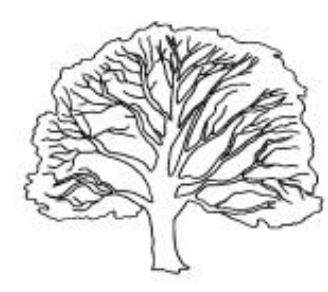

251.
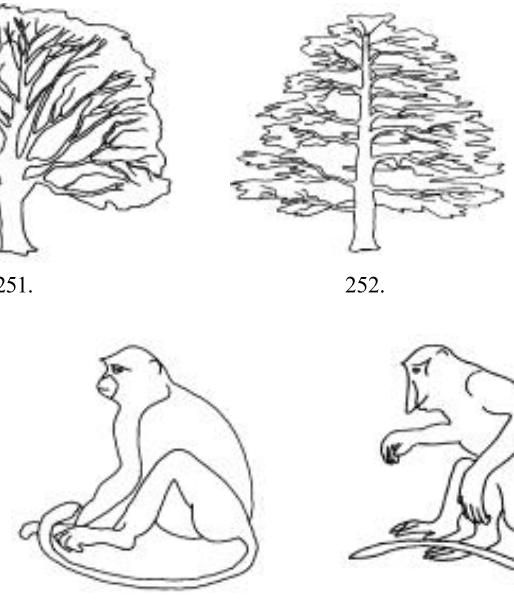

258.

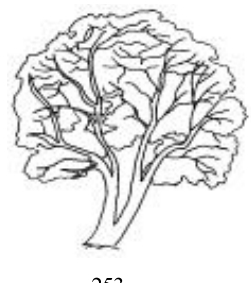

253.

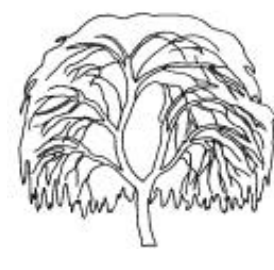

254.

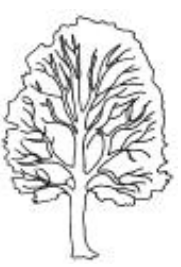

255.

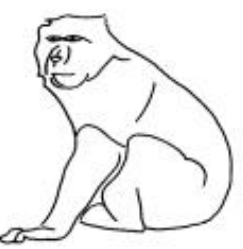

262.

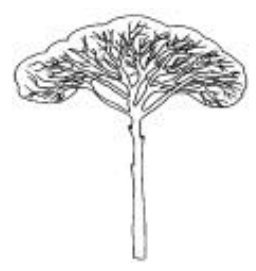

256.

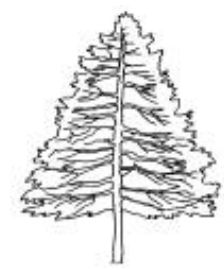

257.

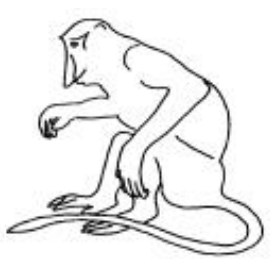

259.

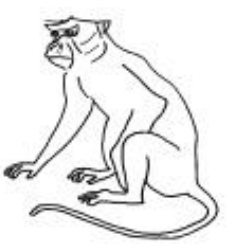

266.

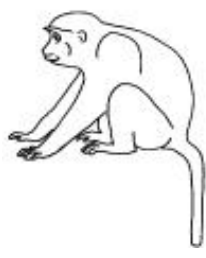

260.

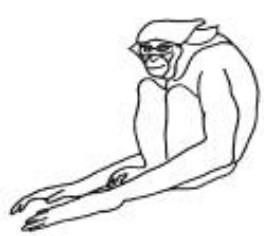

267.

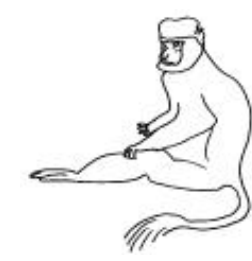

261.

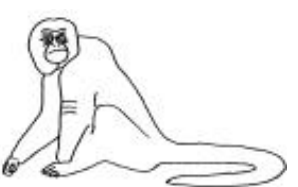

268.

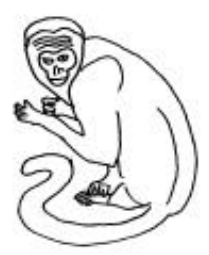

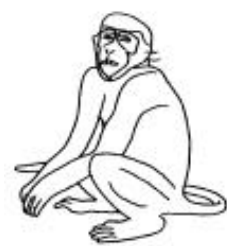

263.

264.

265.

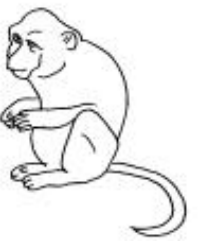




\section{APPENDIX B: Naming results}

Table B1. Most common names for each stimulus (rank numbers corresponding to Appendix A) with name percentage, concept percentage, subordinate percentage, identification percentage, and numbers of subjects ('whale' stands for 'whale-like').

\begin{tabular}{llllll} 
Stimulus Name & $\begin{array}{l}\text { Name } \\
\text { percentage }\end{array}$ & $\begin{array}{l}\text { Concept } \\
\text { percentage }\end{array}$ & $\begin{array}{l}\text { Subordinate } \\
\text { percentage }\end{array}$ & $\begin{array}{l}\text { Identification } \\
\text { percentage }\end{array}$ & $\begin{array}{l}\text { Number } \\
\text { of subject }\end{array}$ \\
\hline
\end{tabular}

\begin{tabular}{|c|c|c|c|c|c|c|}
\hline 1 & glass & 67.60 & 67.60 & 32.40 & 100.00 (glass) & 179 \\
\hline 2 & glass & 74.72 & 74.72 & 24.16 & 98.88 (glass) & 178 \\
\hline 3 & glass & 93.85 & 93.85 & 3.35 & 97.21 (glass) & 179 \\
\hline 4 & wine glass & 53.07 & 53.07 & 0.00 & 100.00 (glass) & 179 \\
\hline 5 & glass & 59.55 & 59.55 & 40.45 & 100.00 (glass) & 178 \\
\hline 6 & glass & 78.65 & 78.65 & 1.22 & 79.78 (glass) & 178 \\
\hline 7 & glass & 51.40 & 51.40 & 19.55 & 70.95 (glass) & 179 \\
\hline 8 & glass & 51.69 & 51.69 & 48.31 & 100.00 (glass) & 178 \\
\hline 9 & glass & 91.62 & 91.62 & 2.79 & 94.41 (glass) & 179 \\
\hline 10 & glass & 78.09 & 78.09 & 1.69 & 79.78 (glass) & 178 \\
\hline 11 & vase & 74.86 & 90.50 & 8.94 & 99.44 (vase) & 179 \\
\hline 12 & vase & 76.40 & 93.26 & 5.62 & 98.88 (vase) & 178 \\
\hline 13 & vase & 70.39 & 92.74 & 6.70 & 99.44 (vase) & 179 \\
\hline 14 & vase & 78.09 & 93.82 & 5.62 & 99.44 (vase) & 178 \\
\hline 15 & vase & 67.60 & 87.71 & 9.50 & 97.21 (vase) & 179 \\
\hline 16 & vase & 50.56 & 78.09 & 18.54 & 96.63 (vase) & 178 \\
\hline 17 & vase & 74.30 & 93.85 & 5.59 & 99.44 (vase) & 179 \\
\hline 18 & vase & 73.60 & 87.64 & 9.55 & 97.19 (vase) & 178 \\
\hline 19 & vase & 66.48 & 78.77 & 13.97 & 92.74 (vase) & 179 \\
\hline 20 & vase & 62.36 & 78.09 & 16.29 & 94.38 (vase) & 178 \\
\hline 21 & vase & 62.01 & 76.54 & 11.73 & 88.27 (vase) & 179 \\
\hline 22 & guitar & 83.24 & 83.24 & 16.76 & 100.00 (guitar) & 179 \\
\hline 23 & guitar & 79.89 & 79.89 & 20.11 & 100.00 (guitar) & 179 \\
\hline 24 & guitar & 77.09 & 77.09 & 22.91 & 100.00 (guitar) & 179 \\
\hline 25 & guitar & 74.86 & 74.86 & 25.14 & 100.00 (guitar) & 179 \\
\hline 26 & guitar & 82.02 & 82.02 & 17.42 & 99.44 (guitar) & 178 \\
\hline 27 & guitar & 87.08 & 87.08 & 12.36 & 99.44 (guitar) & 178 \\
\hline 28 & guitar & 82.02 & 82.02 & 17.42 & 99.44 (guitar) & 178 \\
\hline 29 & guitar & 82.02 & 82.02 & 17.42 & 99.44 (guitar) & 178 \\
\hline 30 & guitar & 73.74 & 73.74 & 26.26 & 100.00 (guitar) & 179 \\
\hline 31 & guitar & 78.21 & 78.21 & 21.79 & 100.00 (guitar) & 179 \\
\hline 32 & guitar & 73.60 & 73.60 & 25.84 & 99.44 (guitar) & 178 \\
\hline 33 & guitar & 72.47 & 72.47 & 26.97 & 99.44 (guitar) & 178 \\
\hline 34 & chair & 99.44 & 99.44 & 0.56 & 100.00 (chair) & 179 \\
\hline 35 & chair & 98.32 & 98.32 & 1.68 & 100.00 (chair) & 179 \\
\hline 36 & chair & 99.44 & 99.44 & 0.56 & 100.00 (chair) & 179 \\
\hline 37 & chair & 100.00 & 100.00 & 0.00 & 100.00 (chair) & 179 \\
\hline 38 & chair & 97.19 & 97.19 & 2.25 & 99.44 (chair) & 178 \\
\hline 39 & chair & 96.63 & 96.63 & 3.37 & 100.00 (chair) & 178 \\
\hline 40 & chair & 96.07 & 96.07 & 3.93 & 100.00 (chair) & 178 \\
\hline 41 & chair & 96.63 & 96.63 & 1.69 & 98.31 (chair) & 178 \\
\hline 42 & chair & 98.32 & 98.32 & 1.68 & 100.00 (chair) & 179 \\
\hline 43 & chair & 100.00 & 100.00 & 0.00 & 100.00 (chair) & 179 \\
\hline 44 & chair & 97.19 & 97.19 & 2.81 & 100.00 (chair) & 178 \\
\hline 45 & table & 69.27 & 69.27 & 30.73 & 100.00 (table) & 179 \\
\hline 46 & table & 92.18 & 92.18 & 7.82 & 100.00 (table) & 179 \\
\hline 47 & table & 97.75 & 97.75 & 2.25 & 100.00 (table) & 178 \\
\hline 48 & table & 87.15 & 87.15 & 12.29 & 99.44 (table) & 179 \\
\hline 49 & table & 79.78 & 79.78 & 20.22 & 100.00 (table) & 178 \\
\hline 50 & table & 79.78 & 80.90 & 19.10 & 100.00 (table) & 178 \\
\hline 51 & table & 75.98 & 75.98 & 16.20 & 92.18 (table) & 179 \\
\hline 52 & table & 96.09 & 96.09 & 3.91 & 100.00 (table) & 179 \\
\hline
\end{tabular}


Table B1 (continued)

\begin{tabular}{llllll}
\hline Stimulus Name & $\begin{array}{l}\text { Name } \\
\text { percentage }\end{array}$ & $\begin{array}{l}\text { Concept } \\
\text { percentage }\end{array}$ & $\begin{array}{l}\text { Subordinate } \\
\text { percentage }\end{array}$ & $\begin{array}{l}\text { Identification } \\
\text { percentage }\end{array}$ & $\begin{array}{l}\text { Number } \\
\text { of subjects }\end{array}$ \\
\hline
\end{tabular}

\begin{tabular}{|c|c|c|c|c|c|c|}
\hline 53 & table & 97.19 & 97.19 & 2.81 & 100.00 (table) & 178 \\
\hline 54 & table & 98.88 & 98.88 & 1.12 & 100.00 (table) & 178 \\
\hline 55 & table & 96.63 & 96.63 & 3.37 & 100.00 (table) & 178 \\
\hline 56 & cupboard & 92.18 & 92.19 & 7.82 & 100.00 (idem) & 179 \\
\hline 57 & cupboard & 80.90 & 81.46 & 17.98 & 99.44 (idem) & 178 \\
\hline 58 & cupboard & 83.24 & 83.24 & 16.76 & 100.00 (idem) & 179 \\
\hline 59 & cupboard & 81.46 & 82.02 & 17.98 & 100.00 (idem) & 178 \\
\hline 60 & cupboard & 79.33 & 79.33 & 20.67 & 100.00 (idem) & 179 \\
\hline 61 & cupboard & 83.80 & 83.80 & 16.20 & 100.00 (idem) & 179 \\
\hline 62 & cupboard & 77.53 & 77.53 & 22.47 & 100.00 (idem) & 178 \\
\hline 63 & cupboard & 61.80 & 62.36 & 37.64 & 100.00 (idem) & 178 \\
\hline 64 & cupboard & 82.12 & 82.12 & 17.88 & 100.00 (idem) & 179 \\
\hline 65 & cupboard & 92.74 & 92.74 & 7.26 & 100.00 (idem) & 179 \\
\hline 66 & cupboard & 88.20 & 88.76 & 11.24 & 100.00 (idem) & 178 \\
\hline 67 & sofa & 75.42 & 94.41 & 5.59 & 100.00 (sofa) & 179 \\
\hline 68 & sofa & 81.01 & 96.65 & 3.35 & 100.00 (sofa) & 179 \\
\hline 69 & sofa & 77.09 & 93.85 & 6.15 & 100.00 (sofa) & 179 \\
\hline 70 & sofa & 74.86 & 96.09 & 3.91 & 100.00 (sofa) & 179 \\
\hline 71 & sofa & 72.47 & 96.07 & 3.93 & 100.00 (sofa) & 178 \\
\hline 72 & sofa & 73.03 & 96.63 & 3.37 & 100.00 (sofa) & 178 \\
\hline 73 & sofa & 74.16 & 98.31 & 1.69 & 100.00 (sofa) & 178 \\
\hline 74 & sofa & 78.09 & 85.96 & 14.04 & 100.00 (sofa) & 178 \\
\hline 75 & sofa & 75.98 & 92.74 & 7.26 & 100.00 (sofa) & 179 \\
\hline 76 & sofa & 91.06 & 91.62 & 5.59 & 97.21 (sofa) & 179 \\
\hline 77 & sofa & 81.46 & 82.02 & 9.55 & 91.57 (sofa) & 178 \\
\hline 78 & sofa & 89.89 & 91.01 & 8.99 & 100.00 (sofa) & 178 \\
\hline 79 & bike & 36.87 & 78.77 & 21.23 & 100.00 (bike) & 179 \\
\hline 80 & bike & 40.22 & 82.12 & 17.88 & 100.00 (bike) & 179 \\
\hline 81 & bike & 30.17 & 80.45 & 19.55 & 100.00 (bike) & 179 \\
\hline 82 & bike & 30.17 & 72.63 & 27.37 & 100.00 (bike) & 179 \\
\hline 83 & bike & 31.28 & 74.86 & 25.14 & 100.00 (bike) & 179 \\
\hline 84 & bike & 42.46 & 81.46 & 18.54 & 100.00 (bike) & 178 \\
\hline 85 & bike & 46.63 & 87.64 & 11.80 & 98.44 (bike) & 178 \\
\hline 86 & bike & 50.00 & 88.22 & 11.80 & 100.00 (bike) & 178 \\
\hline 87 & bike & 46.63 & 91.57 & 8.43 & 100.00 (bike) & 178 \\
\hline 88 & bike & 52.81 & 89.89 & 10.11 & 100.00 (bike) & 178 \\
\hline 89 & automobile & 92.74 & 94.97 & 5.03 & 100.00 (idem) & 179 \\
\hline 90 & automobile & 94.94 & 95.51 & 4.49 & 100.00 (idem) & 178 \\
\hline 91 & automobile & 93.85 & 96.65 & 3.35 & 100.00 (idem) & 179 \\
\hline 92 & automobile & 96.63 & 97.19 & 2.81 & 100.00 (idem) & 178 \\
\hline 93 & automobile & 94.97 & 97.77 & 2.23 & 100.00 (idem) & 179 \\
\hline 94 & automobile & 88.76 & 88.76 & 11.24 & 100.00 (idem) & 178 \\
\hline 95 & automobile & 89.94 & 93.30 & 6.70 & 100.00 (idem) & 179 \\
\hline 96 & automobile & 92.70 & 94.38 & 5.62 & 100.00 (idem) & 178 \\
\hline 97 & automobile & 79.33 & 81.01 & 18.99 & 100.00 (idem) & 179 \\
\hline 98 & automobile & 81.57 & 92.13 & 7.87 & 100.00 (idem) & 178 \\
\hline 99 & automobile & 87.08 & 87.64 & 12.36 & 100.00 (idem) & 178 \\
\hline 100 & train & 66.48 & 66.48 & 28.49 & 94.97 (train) & 179 \\
\hline 101 & train & 65.36 & 65.36 & 34.08 & 99.44 (train) & 179 \\
\hline 102 & train & 83.71 & 83.71 & 15.17 & 98.88 (train) & 178 \\
\hline 103 & train & 92.70 & 92.70 & 4.49 & 97.19 (train) & 178 \\
\hline 104 & train & 93.30 & 93.30 & 6.70 & 100.00 (train) & 179 \\
\hline 105 & train & 93.30 & 93.30 & 6.15 & 99.44 (train) & 179 \\
\hline 106 & train & 92.13 & 92.13 & 4.49 & 96.62 (train) & 178 \\
\hline 107 & train & 80.34 & 80.34 & 17.98 & 98.32 (train) & 178 \\
\hline 108 & train & 96.09 & 96.09 & 2.79 & 98.88 (train) & 179 \\
\hline
\end{tabular}


Table B1 (continued)

\begin{tabular}{llllll}
\hline Stimulus Name & $\begin{array}{l}\text { Name } \\
\text { percentage }\end{array}$ & $\begin{array}{l}\text { Concept } \\
\text { percentage }\end{array}$ & $\begin{array}{l}\text { Subordinate } \\
\text { percentage }\end{array}$ & $\begin{array}{l}\text { Identification } \\
\text { percentage }\end{array}$ & $\begin{array}{l}\text { Number } \\
\text { of subjects }\end{array}$ \\
\hline
\end{tabular}

\begin{tabular}{|c|c|c|c|c|c|c|}
\hline 109 & train & 74.30 & 74.30 & 25.14 & 99.44 (train) & 179 \\
\hline 110 & train & 79.21 & 79.21 & 16.29 & 95.50 (train) & 178 \\
\hline 111 & train & 60.11 & 60.11 & 38.76 & 98.87 (train) & 178 \\
\hline 112 & aircraft & 94.41 & 94.41 & 5.59 & 100.00 (aircraft) & 179 \\
\hline 113 & aircraft & 92.74 & 92.74 & 7.26 & 100.00 (aircraft) & 179 \\
\hline 114 & aircraft & 83.15 & 87.08 & 12.92 & 100.00 (aircraft) & 178 \\
\hline 115 & aircraft & 73.03 & 73.60 & 26.40 & 100.00 (aircraft) & 178 \\
\hline 116 & aircraft & 79.89 & 79.89 & 15.64 & 95.33 (aircraft) & 179 \\
\hline 117 & aircraft & 87.71 & 87.71 & 12.29 & 100.00 (aircraft) & 179 \\
\hline 118 & aircraft & 50.00 & 50.56 & 48.88 & 99.44 (aircraft) & 178 \\
\hline 119 & aircraft & 89.33 & 89.89 & 10.11 & 100.00 (aircraft) & 178 \\
\hline 120 & aircraft & 88.27 & 88.83 & 11.17 & 100.00 (aircraft) & 179 \\
\hline 121 & aircraft & 93.82 & 93.82 & 6.18 & 100.00 (aircraft) & 178 \\
\hline 122 & aircraft & 87.08 & 88.76 & 11.24 & 100.00 (aircraft) & 178 \\
\hline 123 & bicycle & 87.15 & 87.71 & 12.29 & 100.00 (bicycle) & 179 \\
\hline 124 & bicycle & 91.62 & 91.62 & 8.38 & 100.00 (bicycle) & 179 \\
\hline 125 & bicycle & 87.64 & 88.76 & 11.24 & 100.00 (bicycle) & 178 \\
\hline 126 & bicycle & 88.20 & 88.20 & 9.55 & 97.75 (bicycle) & 178 \\
\hline 127 & bicycle & 72.63 & 72.63 & 27.37 & 100.00 (bicycle) & 179 \\
\hline 128 & bicycle & 97.21 & 97.21 & 2.79 & 100.00 (bicycle) & 179 \\
\hline 129 & bicycle & 93.82 & 93.82 & 6.18 & 100.00 (bicycle) & 178 \\
\hline 130 & bicycle & 87.64 & 88.76 & 11.24 & 100.00 (bicycle) & 178 \\
\hline 131 & ship & 49.16 & 96.65 & 3.35 & 100.00 (ship) & 179 \\
\hline 132 & boat & 46.93 & 93.30 & 6.70 & 100.00 (boat) & 179 \\
\hline 133 & ship & 50.56 & 88.20 & 11.80 & 100.00 (ship) & 178 \\
\hline 134 & ship & 46.37 & 92.70 & 7.30 & 100.00 (ship) & 178 \\
\hline 135 & boat & 45.25 & 81.01 & 18.99 & 100.00 (boat) & 179 \\
\hline 136 & boat & 50.84 & 95.53 & 4.47 & 100.00 (boat) & 179 \\
\hline 137 & ship & 46.63 & 80.90 & 19.10 & 100.00 (ship) & 178 \\
\hline 138 & ship & 50.00 & 96.07 & 3.93 & 100.00 (ship) & 178 \\
\hline 139 & ship & 48.88 & 84.83 & 12.36 & 97.19 (ship) & 178 \\
\hline 140 & boat & 44.13 & 92.70 & 6.74 & 99.44 (boat) & 178 \\
\hline 141 & ship & 45.25 & 89.94 & 6.70 & 96.65 (ship) & 179 \\
\hline 142 & boat & 43.02 & 84.36 & 15.64 & 96.65 (boat) & 179 \\
\hline 143 & hamster & 26.82 & 26.82 & 0.00 & 94.97 (rodent) & 179 \\
\hline 144 & rat & 27.37 & 27.37 & 0.56 & 98.32 (rodent) & 179 \\
\hline 145 & rat & 46.63 & 46.63 & 0.56 & 98.88 (rodent) & 178 \\
\hline 146 & rat & 40.78 & 40.78 & 0.00 & 99.44 (rodent) & 178 \\
\hline 147 & rat & 65.36 & 65.36 & 0.00 & 93.85 (rodent) & 179 \\
\hline 148 & rat & 59.22 & 59.22 & 0.56 & 96.65 (rodent) & 179 \\
\hline 149 & rat & 59.78 & 59.78 & 0.56 & 96.65 (rodent) & 179 \\
\hline 150 & mouse & 39.11 & 39.11 & 2.23 & 98.88 (rodent) & 178 \\
\hline 151 & rat & 48.88 & 49.44 & 1.12 & 99.44 (rodent) & 178 \\
\hline 152 & rat & 46.07 & 46.07 & 0.56 & 98.31 (rodent) & 178 \\
\hline 153 & rat & 64.80 & 64.80 & 0.56 & 97.21 (rodent) & 179 \\
\hline 154 & rabbit & 96.09 & 96.09 & 1.12 & 97.21 (rabbit) & 179 \\
\hline 155 & rabbit & 91.62 & 91.62 & 6.15 & 97.77 (rabbit) & 179 \\
\hline 156 & rabbit & 92.70 & 93.26 & 0.56 & 93.82 (rabbit) & 178 \\
\hline 157 & rabbit & 98.31 & 98.88 & 0.00 & 98.88 (rabbit) & 178 \\
\hline 158 & rabbit & 91.06 & 91.06 & 7.82 & 98.88 (rabbit) & 179 \\
\hline 159 & rabbit & 97.21 & 97.21 & 0.56 & 97.77 (rabbit) & 179 \\
\hline 160 & rabbit & 97.19 & 97.19 & 1.69 & 98.88 (rabbit) & 178 \\
\hline 161 & rabbit & 96.63 & 96.63 & 0.56 & 97.19 (rabbit) & 178 \\
\hline 162 & rabbit & 94.97 & 94.97 & 1.68 & 96.65 (rabbit) & 179 \\
\hline 163 & rabbit & 90.45 & 90.45 & 4.49 & 94.94 (rabbit) & 178 \\
\hline 164 & fish & 43.58 & 43.58 & 2.79 & 53.07 ('whale') & 179 \\
\hline
\end{tabular}


Table B1 (continued)

\begin{tabular}{llllll}
\hline Stimulus Name & $\begin{array}{l}\text { Name } \\
\text { percentage }\end{array}$ & $\begin{array}{l}\text { Concept } \\
\text { percentage }\end{array}$ & $\begin{array}{l}\text { Subordinate } \\
\text { percentage }\end{array}$ & $\begin{array}{l}\text { Identification } \\
\text { percentage }\end{array}$ & $\begin{array}{l}\text { Number } \\
\text { of subjects }\end{array}$ \\
\hline
\end{tabular}

\begin{tabular}{|c|c|c|c|c|c|c|}
\hline 165 & fish & 46.37 & 46.37 & 2.79 & 53.07 ('whale') & 179 \\
\hline 166 & fish & 40.45 & 40.45 & 3.37 & 53.93 ('whale') & 179 \\
\hline 167 & dolphin & 60.11 & 60.11 & 0.00 & 74.72 ('whale') & 178 \\
\hline 168 & dolphin & 64.25 & 64.80 & 0.00 & 67.60 ('whale') & 179 \\
\hline 169 & dolphin & 63.13 & 63.13 & 0.00 & 73.18 ('whale') & 179 \\
\hline 170 & dolphin & 67.42 & 67.42 & 0.00 & 76.40 ('whale') & 178 \\
\hline 171 & dolphin & 67.42 & 67.42 & 0.00 & 72.47 ('whale') & 178 \\
\hline 172 & dolphin & 47.49 & 47.49 & 0.00 & 72.63 ('whale') & 179 \\
\hline 173 & dolphin & 46.93 & 47.49 & 0.00 & 65.92 ('whale') & 179 \\
\hline 174 & fish/whale & 30.17 & 30.17 & $16.76 / 21.79$ & 52.25 ('whale') & 178 \\
\hline 175 & horse & 86.59 & 86.59 & 13.41 & 100.00 (horse) & 179 \\
\hline 176 & horse & 94.38 & 94.38 & 5.62 & 100.00 (horse) & 178 \\
\hline 177 & horse & 56.42 & 56.42 & 43.58 & 100.00 (horse) & 179 \\
\hline 178 & horse & 65.73 & 65.73 & 34.27 & 100.00 (horse) & 178 \\
\hline 179 & horse & 71.51 & 71.51 & 27.93 & 99.44 (horse) & 179 \\
\hline 180 & horse & 66.48 & 66.48 & 33.52 & 100.00 (horse) & 178 \\
\hline 181 & horse & 91.57 & 91.57 & 8.43 & 100.00 (horse) & 178 \\
\hline 182 & horse & 88.76 & 88.76 & 11.24 & 100.00 (horse) & 178 \\
\hline 183 & horse & 94.97 & 94.97 & 5.03 & 100.00 (horse) & 179 \\
\hline 184 & horse & 92.74 & 92.74 & 6.70 & 99.44 (horse) & 179 \\
\hline 185 & horse & 92.13 & 92.13 & 7.87 & 100.00 (horse) & 178 \\
\hline 186 & horse & 92.70 & 92.70 & 7.30 & 100.00 (horse) & 178 \\
\hline 187 & $\operatorname{dog}$ & 98.88 & 98.88 & 1.12 & $100.00(\mathrm{dog})$ & 179 \\
\hline 188 & dog & 67.04 & 67.04 & 32.40 & $99.44(\mathrm{dog})$ & 179 \\
\hline 189 & $\operatorname{dog}$ & 93.26 & 93.26 & 6.18 & $99.44(\operatorname{dog})$ & 178 \\
\hline 190 & $\operatorname{dog}$ & 81.46 & 81.46 & 17.98 & $99.44(\operatorname{dog})$ & 178 \\
\hline 191 & $\operatorname{dog}$ & 98.88 & 98.88 & 1.12 & $100.00(\mathrm{dog})$ & 179 \\
\hline 192 & $\operatorname{dog}$ & 93.26 & 94.38 & 5.06 & $99.44(\operatorname{dog})$ & 178 \\
\hline 193 & $\operatorname{dog}$ & 75.42 & 75.42 & 22.35 & $97.77(\mathrm{dog})$ & 179 \\
\hline 194 & $\operatorname{dog}$ & 86.52 & 86.52 & 12.92 & $99.44(\operatorname{dog})$ & 178 \\
\hline 195 & $\operatorname{dog}$ & 87.71 & 87.71 & 8.94 & $96.65(\operatorname{dog})$ & 179 \\
\hline 196 & $\operatorname{dog}$ & 92.70 & 92.70 & 6.18 & $98.88(\mathrm{dog})$ & 178 \\
\hline 197 & $\operatorname{dog}$ & 97.75 & 97.75 & 1.69 & $99.44(\operatorname{dog})$ & 178 \\
\hline 198 & fish & 92.18 & 92.18 & 7.82 & 100.00 (fish) & 179 \\
\hline 199 & fish & 92.18 & 92.18 & 7.82 & 100.00 (fish) & 179 \\
\hline 200 & fish & 99.44 & 99.44 & 0.56 & 100.00 (fish) & 178 \\
\hline 201 & fish & 95.51 & 96.07 & 3.93 & 100.00 (fish) & 178 \\
\hline 202 & fish & 97.77 & 97.77 & 2.23 & 100.00 (fish) & 179 \\
\hline 203 & fish & 96.68 & 97.19 & 2.81 & 100.00 (fish) & 178 \\
\hline 204 & fish & 92.18 & 92.18 & 7.82 & 100.00 (fish) & 179 \\
\hline 205 & fish & 99.44 & 99.44 & 0.56 & 100.00 (fish) & 179 \\
\hline 206 & fish & 99.44 & 100.00 & 0.00 & 100.00 (fish) & 178 \\
\hline 207 & fish & 98.88 & 98.88 & 1.12 & 100.00 (fish) & 178 \\
\hline 208 & fish & 82.12 & 82.12 & 17.88 & 100.00 (fish) & 179 \\
\hline 209 & fish & 98.88 & 98.88 & 1.12 & 100.00 (fish) & 178 \\
\hline 210 & butterfly & 97.77 & 97.77 & 2.23 & 100.00 (butterfly) & 179 \\
\hline 211 & butterfly & 83.71 & 83.71 & 14.61 & 98.32 (butterfly) & 178 \\
\hline 212 & butterfly & 68.72 & 68.72 & 28.49 & 97.21 (butterfly) & 179 \\
\hline 213 & butterfly & 75.42 & 75.42 & 23.46 & 98.88 (butterfly) & 179 \\
\hline 214 & butterfly & 87.08 & 87.08 & 11.24 & 98.32 (butterfly) & 178 \\
\hline 215 & butterfly & 97.75 & 97.75 & 1.69 & 99.44 (butterfly) & 178 \\
\hline 216 & butterfly & 91.06 & 91.06 & 8.94 & 100.00 (butterfly) & 179 \\
\hline 217 & butterfly & 98.32 & 98.32 & 1.12 & 99.44 (butterfly) & 179 \\
\hline 218 & butterfly & 98.88 & 98.88 & 0.56 & 99.44 (butterfly) & 178 \\
\hline 219 & butterfly & 99.44 & 99.44 & 0.00 & 99.44 (butterfly) & 178 \\
\hline 220 & beetle & 69.83 & 79.33 & 0.56 & 79.89 (beetle) & 179 \\
\hline
\end{tabular}


Table B1 (continued)

\begin{tabular}{llllll}
\hline Stimulus Name & $\begin{array}{l}\text { Name } \\
\text { percentage }\end{array}$ & $\begin{array}{l}\text { Concept } \\
\text { percentage }\end{array}$ & $\begin{array}{l}\text { Subordinate } \\
\text { percentage }\end{array}$ & $\begin{array}{l}\text { Identification } \\
\text { percentage }\end{array}$ & $\begin{array}{l}\text { Number } \\
\text { of subjects }\end{array}$ \\
\hline
\end{tabular}

\begin{tabular}{|c|c|c|c|c|c|c|}
\hline 221 & beetle & 75.28 & 82.58 & 1.12 & 83.71 (beetle) & 178 \\
\hline 222 & beetle & 66.48 & 82.12 & 3.91 & 86.03 (beetle) & 179 \\
\hline 223 & beetle & 78.65 & 86.52 & 2.81 & 89.33 (beetle) & 178 \\
\hline 224 & beetle & 69.83 & 80.45 & 1.68 & 82.12 (beetle) & 179 \\
\hline 225 & beetle & 75.84 & 83.15 & 3.37 & 86.52 (beetle) & 178 \\
\hline 226 & beetle & 67.04 & 76.54 & 1.68 & 78.21 (beetle) & 179 \\
\hline 227 & beetle & 64.25 & 73.74 & 1.12 & 74.86 (beetle) & 179 \\
\hline 228 & beetle & 78.09 & 85.39 & 1.12 & 86.52 (beetle) & 178 \\
\hline 229 & beetle & 73.60 & 79.78 & 5.06 & 84.83 (beetle) & 178 \\
\hline 230 & bird & 88.33 & 92.18 & 7.82 & 100.00 (bird) & 179 \\
\hline 231 & bird & 97.19 & 97.19 & 2.81 & 100.00 (bird) & 178 \\
\hline 232 & bird & 94.97 & 95.51 & 4.49 & 100.00 (bird) & 179 \\
\hline 233 & bird & 94.94 & 95.51 & 4.49 & 100.00 (bird) & 178 \\
\hline 234 & bird & 88.83 & 90.50 & 9.50 & 100.00 (bird) & 179 \\
\hline 235 & bird & 90.50 & 93.30 & 6.70 & 100.00 (bird) & 179 \\
\hline 236 & bird & 94.94 & 94.94 & 5.06 & 100.00 (bird) & 178 \\
\hline 237 & bird & 93.26 & 95.51 & 4.49 & 100.00 (bird) & 178 \\
\hline 238 & bird & 92.18 & 94.41 & 5.59 & 100.00 (bird) & 179 \\
\hline 239 & bird & 93.82 & 94.94 & 5.06 & 100.00 (bird) & 178 \\
\hline 240 & bird & 97.19 & 97.19 & 2.81 & 100.00 (bird) & 178 \\
\hline 241 & chicken & 97.21 & 97.21 & 2.79 & 100.00 (chicken) & 179 \\
\hline 242 & chicken & 94.97 & 94.97 & 5.03 & 100.00 (chicken) & 179 \\
\hline 243 & chicken & 94.38 & 94.38 & 5.62 & 100.00 (chicken) & 178 \\
\hline 244 & chicken & 92.70 & 92.70 & 7.30 & 100.00 (chicken) & 178 \\
\hline 245 & chicken & 94.41 & 94.97 & 5.03 & 100.00 (chicken) & 179 \\
\hline 246 & chicken & 92.01 & 92.01 & 8.99 & 100.00 (chicken) & 178 \\
\hline 247 & chicken & 88.83 & 88.83 & 11.17 & 100.00 (chicken) & 178 \\
\hline 248 & chicken & 75.28 & 75.28 & 24.72 & 100.00 (chicken) & 178 \\
\hline 249 & chicken & 77.65 & 77.65 & 22.35 & 100.00 (chicken) & 179 \\
\hline 250 & chicken & 85.96 & 86.52 & 13.48 & 100.00 (chicken) & 178 \\
\hline 251 & tree & 95.53 & 95.53 & 4.47 & 100.00 (tree) & 179 \\
\hline 252 & tree & 94.41 & 94.41 & 5.59 & 100.00 (tree) & 179 \\
\hline 253 & tree & 93.26 & 93.26 & 5.06 & 100.00 (tree) & 178 \\
\hline 254 & tree & 65.73 & 65.73 & 34.27 & 100.00 (tree) & 178 \\
\hline 255 & tree & 97.21 & 97.21 & 2.79 & 100.00 (tree) & 179 \\
\hline 256 & tree & 94.97 & 95.53 & 4.47 & 100.00 (tree) & 179 \\
\hline 257 & tree & 57.87 & 57.85 & 41.57 & 99.44 (tree) & 178 \\
\hline 258 & monkey & 96.65 & 98.32 & 1.68 & 100.00 (monkey) & 179 \\
\hline 259 & monkey & 93.30 & 93.85 & 6.15 & 100.00 (monkey) & 179 \\
\hline 260 & monkey & 94.38 & 98.31 & 1.12 & 99.44 (monkey) & 178 \\
\hline 261 & monkey & 96.07 & 97.75 & 1.69 & 99.44 (monkey) & 178 \\
\hline 262 & monkey & 94.41 & 94.97 & 5.03 & 100.00 (monkey) & 179 \\
\hline 263 & monkey & 96.65 & 98.32 & 1.68 & 100.00 (monkey) & 179 \\
\hline 264 & monkey & 85.96 & 85.96 & 13.48 & 99.44 (monkey) & 178 \\
\hline 265 & monkey & 83.71 & 97.75 & 1.69 & 99.44 (monkey) & 178 \\
\hline 266 & monkey & 98.32 & 98.32 & 1.66 & 100.00 (monkey) & 179 \\
\hline 267 & monkey & 95.51 & 96.63 & 2.81 & 99.44 (monkey) & 178 \\
\hline 268 & monkey & 97.77 & 97.77 & 2.23 & 100.00 (monkey) & 179 \\
\hline 269 & monkey & 94.38 & 96.63 & 2.81 & 99.44 (monkey) & 178 \\
\hline
\end{tabular}


